GEOLOGIC REPORT 74

MINERAL PREPARATION, GRANT GOLD MINE, ALASKA

By

C.N. Conwell

$-\cdots \cdots----\cdots \cdots-$

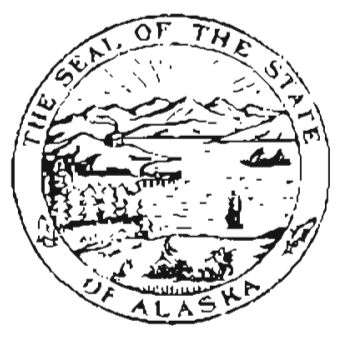

COLLEGE, ALASKA 1982 


\section{STATE OF ALASKA}

Jay S. Hammond, Governor

John W. Katz, Commissioner. Dept. of Natural Resources

Geoffrey Haynes, Depuly Conmissioner

Ross G. Schaff, Slate Coologisl

Cover photo: Head frame. Granc Wine. Vicw lo south.

Available from Aluska Division of Gexlogical and Geuphysical Surveys, P.O Box 80007, College, 99708; 323 F, 4th. Anchorage, 99501: P.O. Box 2438, Ketchikan, 99901 i and 230 So. Franklin, Juneau. 99811 . Cost: $\$ 2$. 


\section{CONTENTS}

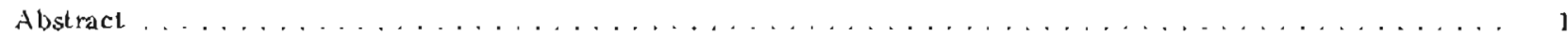

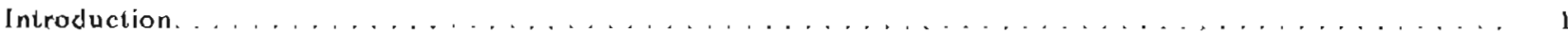

Head samples . . . . . . . . . . . . . . . . . . . . . . . . . . . . . . . .

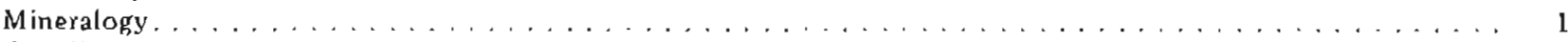

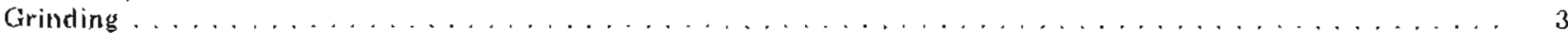

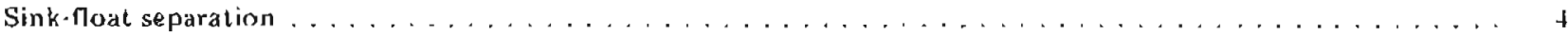

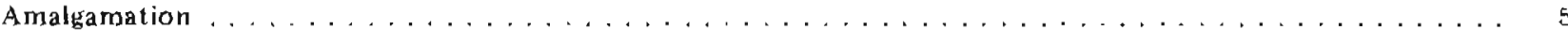

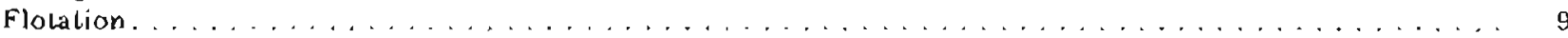

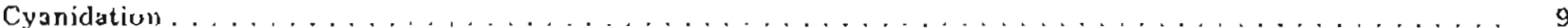

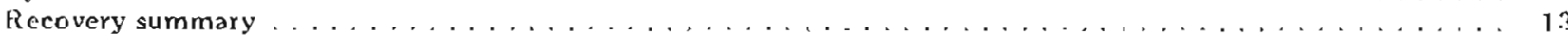

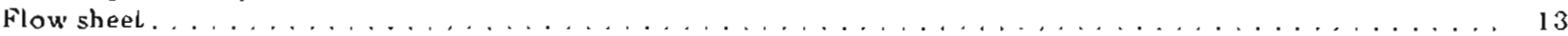

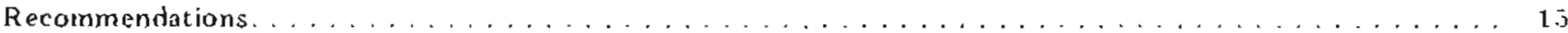

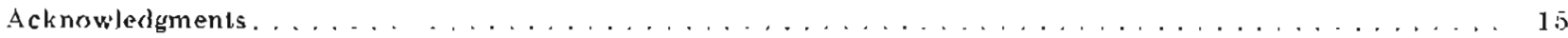

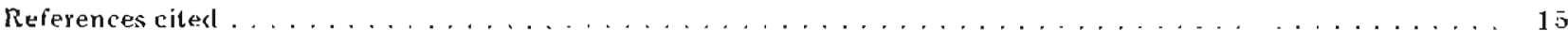

\section{FIGURES}

Figure 1. Pholomicrographs of gold from the Grant Gold Mine $\ldots \ldots \ldots \ldots \ldots$

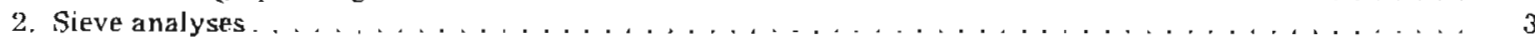

3. Graph comparing the grindability of Grant Gold Mine ore with a hard ore and a medium ore. . . . . 3

4 . Cold and silver values of the Moat fraction (tails) for each size fraction . . . . . . . . . . . . . 8

5. Percent of gold and silver recovered in the sink fraction (concentrate) for each size fraction . . . . . 8

6. Gold and silver values of Hoat l'ractions from sink-float separations (tails), sample $2 \ldots \ldots$

7. Percent, of gold and silver recovered in pach sink-size fraction from sink-floal heavy-liciuicl separations, sample 2

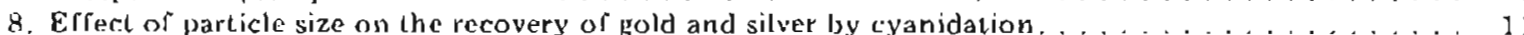

9. Effect of dissolution time and addition of cyanide on the recovery of gold and silver . . . . . . . . 12

10. Flow sheet to 50 -tpd gold fotation conecntrator with a 4 thd batch cyanide circuit. . . . . . . . 14

\section{TABLES}

Tolsle 1 Sieve analysis of ore reduced to minus 10 mesh in a rolls crusher $\ldots \ldots \ldots$

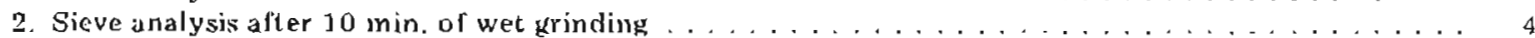

3. Sieve analysis after $20 \mathrm{~min}$ of wet grinding $\ldots \ldots \ldots \ldots \ldots$

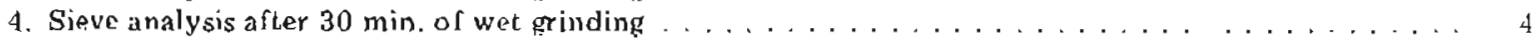

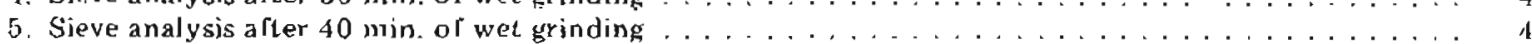

6. Assay of value of fractions and percent of total gold in each size fraction. . . . . . . . . . . . 5

7. Sink-hoat weights, gold assay values, and percent gold recovered, sample $1 \ldots \ldots \ldots$

8. Sink-lloal weights. silver assay values, and percent silver recovered, sample $1 \ldots \ldots \ldots$

9. Sink-hoat weights, gold assens values, and percent gold recovered, sample $2 \ldots \ldots \ldots$

10. Sink-hoal weights and silver assay values, sample $2 \ldots \ldots \ldots \ldots \ldots$

11. Amalgamation test 1 sample $1 \ldots \ldots \ldots \ldots \ldots \ldots \ldots$

12. Amalgamation test 2 sample $1 \ldots \ldots \ldots \ldots \ldots$

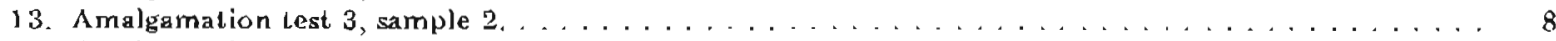

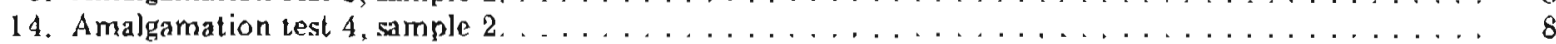

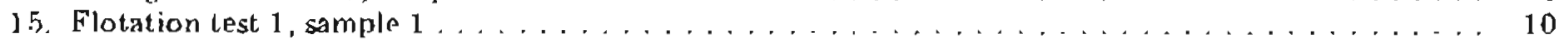

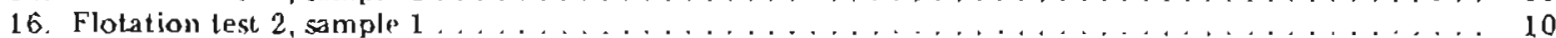

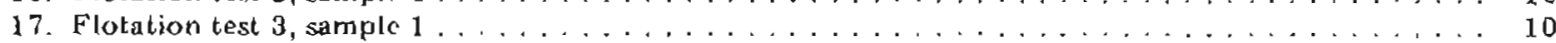

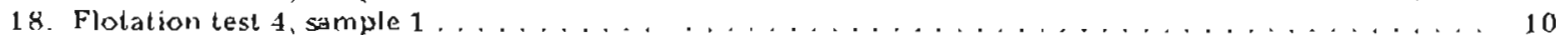

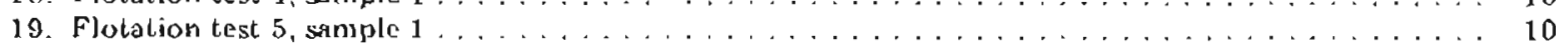

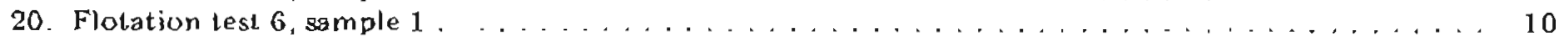

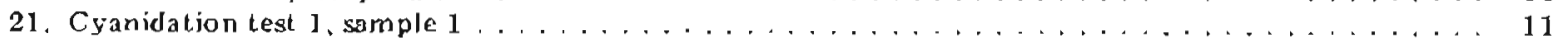

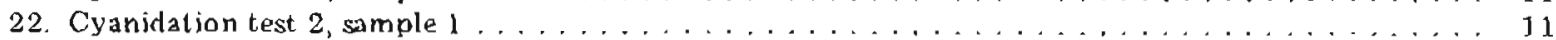

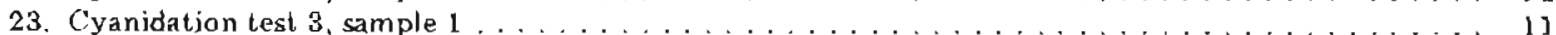

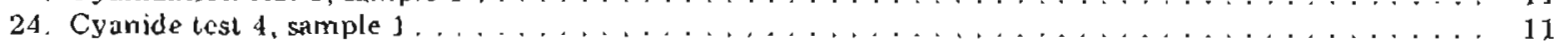

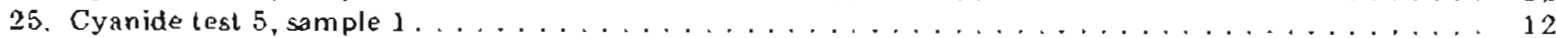

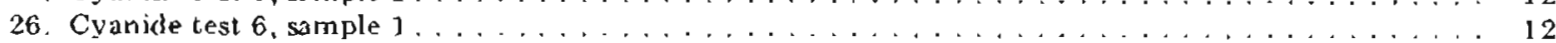

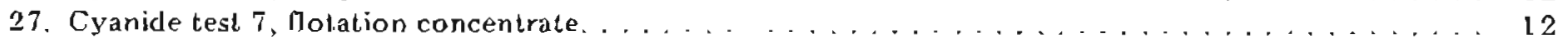

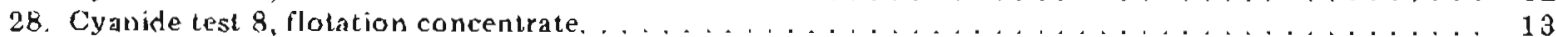

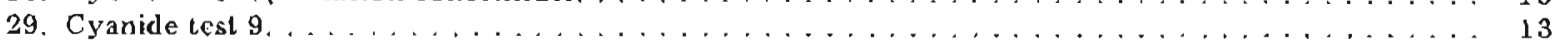

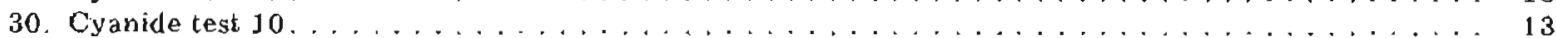




\title{
MINERAL PREPARATION, GRANT GOLD MLNE, ALASKA
}

\author{
By \\ C.N. Conwell, DGGS'
}

\begin{abstract}
The gold in the quartz veins of the Grant Mine can be recovered by gravity separation, amalgamation, nota. tion, or cyanidation. It liberates at a minus 65 -mesh grind.

Gravity separation or amalgamation (or both) will recover aboul, 70 percent of the gold, but a 95 -percent recovery can be expected from either flotation or cyanidation.

The best recovery in the hench-scale test was obtained by first removing the coarse gold by amalgama. tion and then recovering the fine gold by cyanidation.

The mineral preparation tests completed indicate an attractive recovery by froth flotation without pretreatment for the removal of coarse gold, Grinding to minus 65 mesh appears to be adequate.

An alternative method not explored in this study is cyanidation with less comminution. Usually, cyanida. tion plants cost more to build than Motation plants, but if enough gold and silver could be recovered without grinding, cyanide leaching might be warranted.

The Motation producl can be either treated by cyanidation or sold to a smelter. The cyanidation product is precious-metal bullion.
\end{abstract}

\section{INTRODUCTION}

The Grant Mine is located about 15 miles north. wesl of Fairbanks, Alaska. The free-milling gold ore in this deposit may be representative of gold ores elsewhere in the Ester Dome area, and holders of nearby claims may wish to examıne this mineral preparacion study to obtain the optimum gold recovery at the lowest plant investment.

The scope of the work includes grindability, screen analyses, sink-float separations (gravity), amalgamation. notation, and cyanidation tesis.

\section{HEAD SAMPLES}

Two 75-lb samples vere collected from a slope on the $200-\mathrm{ft}$ level. The intent was to obtain a sample diluted by wall rock io approximate the mill heads of ore treated in 1980, which averaged 0.45 oziton gold (Anselmo. 1981). The average of (wo assays was:

\footnotetext{
'DGGS mining engmeer. College. Alaska 99708.
}

$\begin{array}{lll}\text { Gold } & . & 0.452 \text { oz/Lon" } \\ \text { Silver } & - & 0.665 " \\ \text { Copper } & - & 0.006 \text { percent } \\ \text { Lead } & . & 0.049 " \\ \text { Zinc } & - & 0.014 " \\ \text { Antimony } & . & 0.015 " \\ \text { Arsenic } & . & 0.595 "\end{array}$

*Troy oz per short ton

The first sample approximated the ore being milled. so it was used in nearly all of the testing.

This second sample was taken by making several channel cuts across a 1-ft-wide quartz vein. This material assayed:

$\begin{array}{lll}\text { Giold } & - & 2.14 \text { oziton } \\ \text { Silver } & - & 0.16 \text { " } \\ \text { Lead } & . & 0.06-\text { percent } \\ \text { Copper } & - & 0.004 \text { " } \\ \text { Zinc } & - & 0.016 ~ " \\ \text { Antimony } & - & 0.028 \text { " } \\ \text { Arsenic } & - & 0.538 \text { " }\end{array}$

\section{MINERALOGY}

The Grant Mine ore occurs as fracture-tilling vein deposits. The principal structures are the Irishman vein system and the O'Dea breccia zone (Bundtzen and Kline, 1981). The ore for the mill tests was taken from the latter zone on the 200-1t level.

The principal gangue minerals are quartz. geothite, and muscovite. 'The principal sulfide mineral in the samples is arsenopyrite, about 1.2 percent by weight. Sphalerite and galena are present. Other heavy minerals are siderite, rutile, zircon, tourmaline, garnet. and magnetite. Trace amounls of scheelite and cinnabar were detected. The principal value is free gold, but assays indicate an unidentified silver mineral present. DGGS assayer D.R. Slein (oral commun., 1981) stated that the fineness of the gold was about 830 . Parting the gold recovered by amalgamation indicates a similar fineness.

Photomicrographs of the gold grains illustrate their size and shape (fig, 1). Grains $1 \mathrm{~A}$ and 1B are from polished sections and sliow the gold occurring as discrete grains in a quart\% matrix. Figures $1 C, 1 D$, and $1 E$ are polished grain mounts in an epoxy matrix with gold 


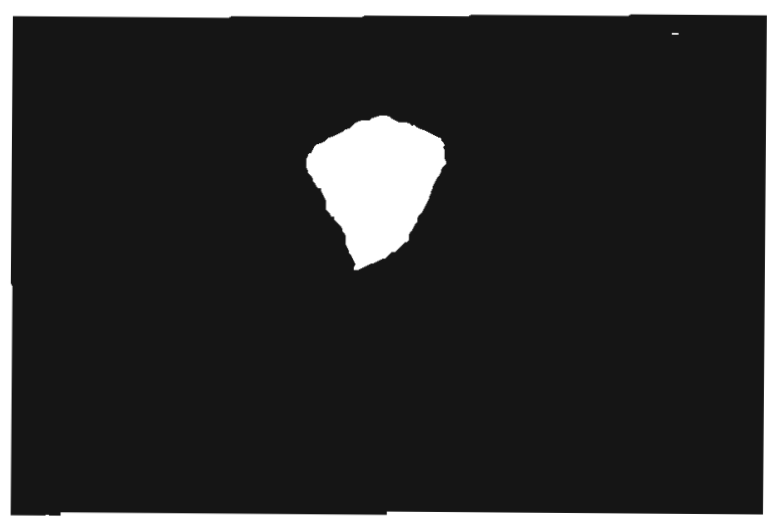

A

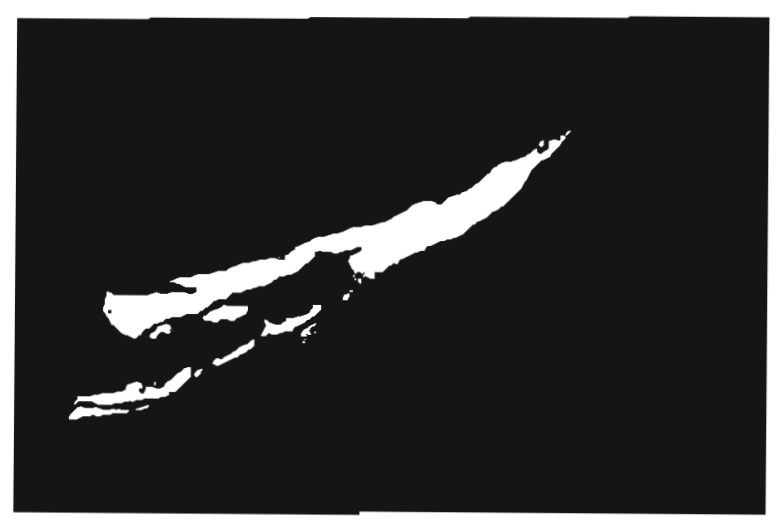

C

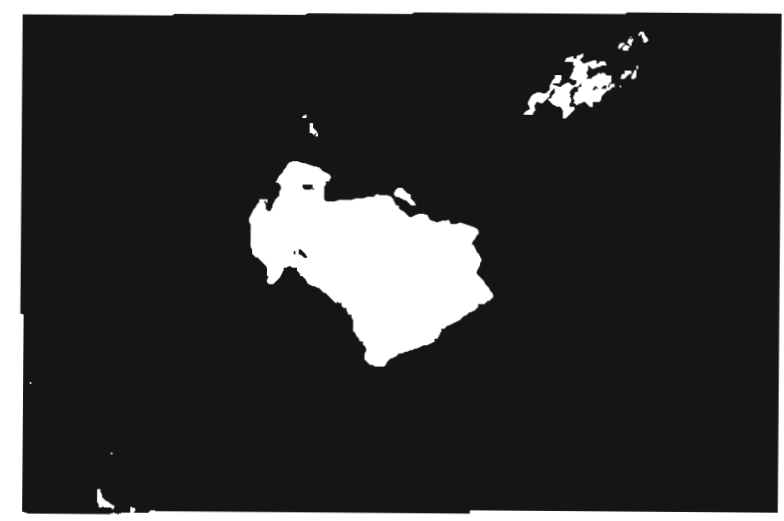

B

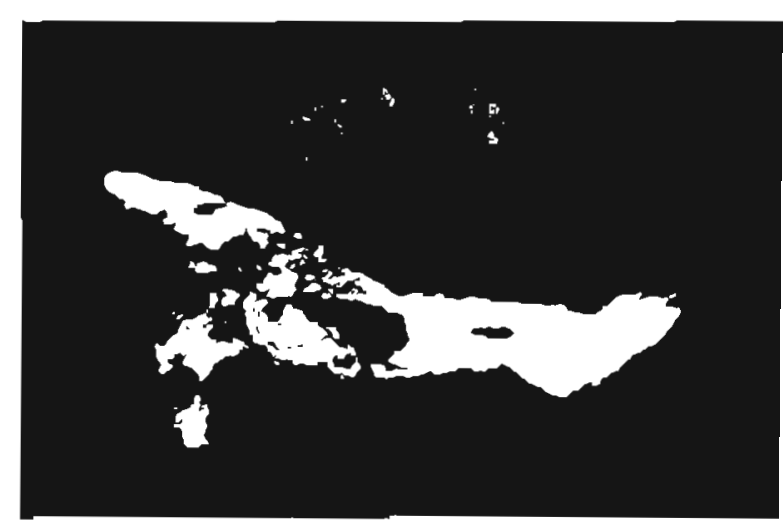

D

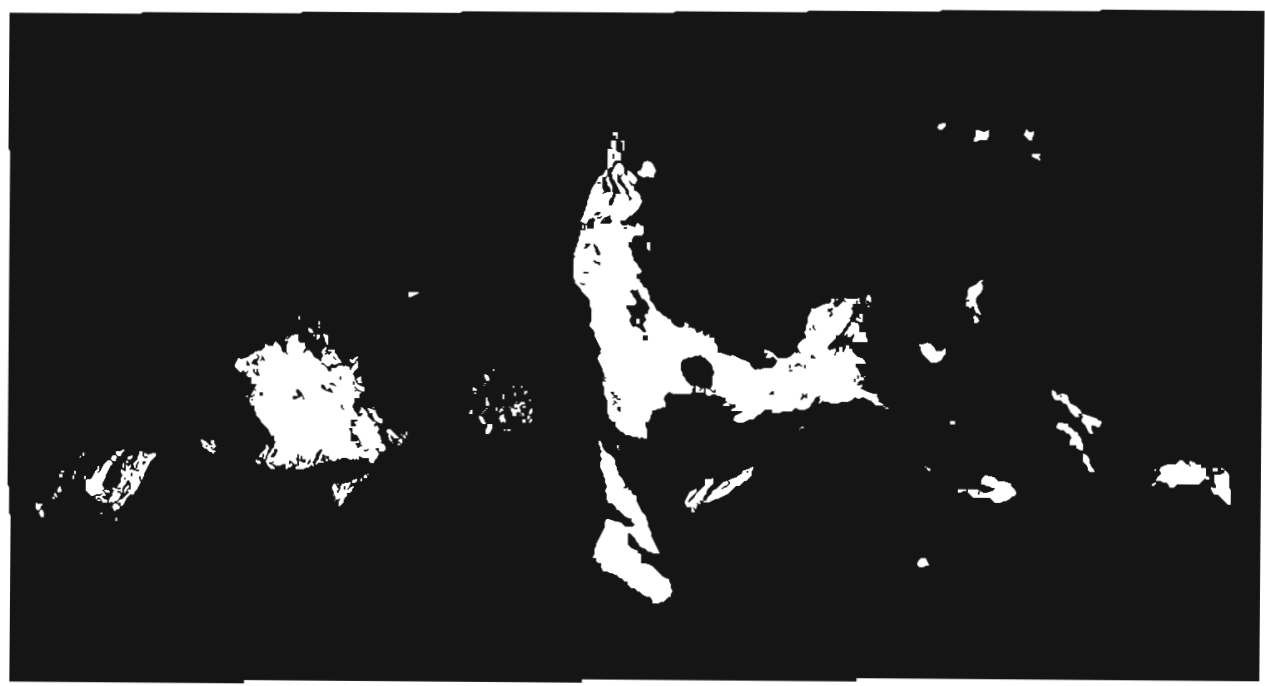

$E$

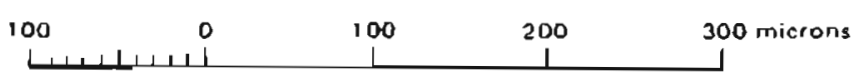

Figure 1. Photomicrographs of gold from the Grant Gold Mine. A and B - Gold grams in a quartz matrix (polished section): $C^{\prime}, D$, and $E \cdot$ Gold grains from sink product in a plastic matrix. 


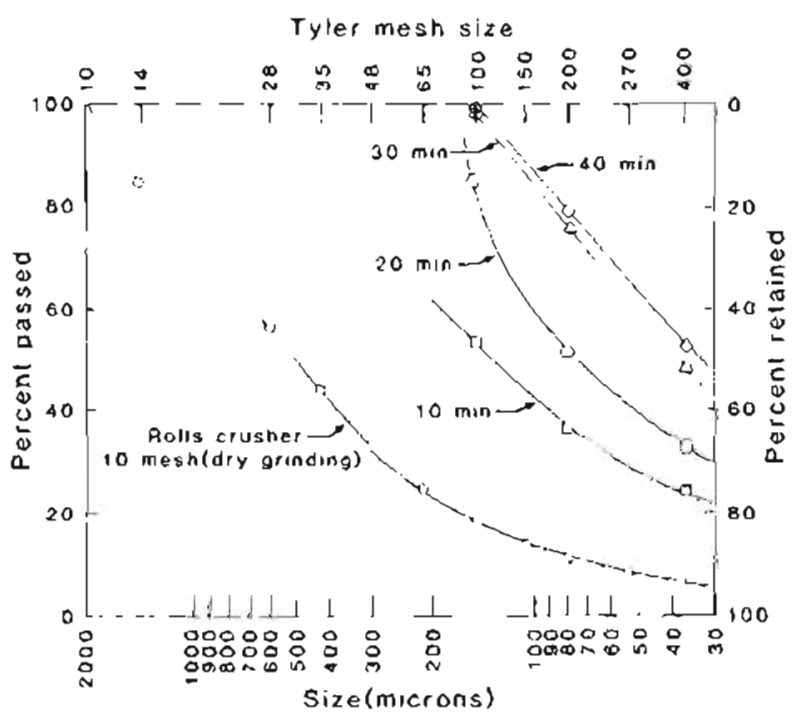

laigure 2. Sieve analyses. Sample reduced to minus 10 mesh in a rolls erusher and then wel ground for $10,20,30$, and $40 \mathrm{~min}$.

grains Mallened by grinding balis. The photonicrographs indicate that the gold, which is confined to quartz, was liberaled al a minus 65-mesh grind. A lew wires as small as 20 microns were found in an amalyamation producl. and some parlicles as large as 1,000 microus were identilied in a concetotrate al the mine.

\section{GRINDING}

The grinding characterstic was determined by a method suggesled in Denver E,qupment Co. Bulletin B2. $334 \mathrm{~A}$. First, the samples are crushed to minus 10 mesh and then wet ground in a ball mill. 'The percentage of material passing a 200-mesl screen is then compared with a standard in the bulletin. This compari-

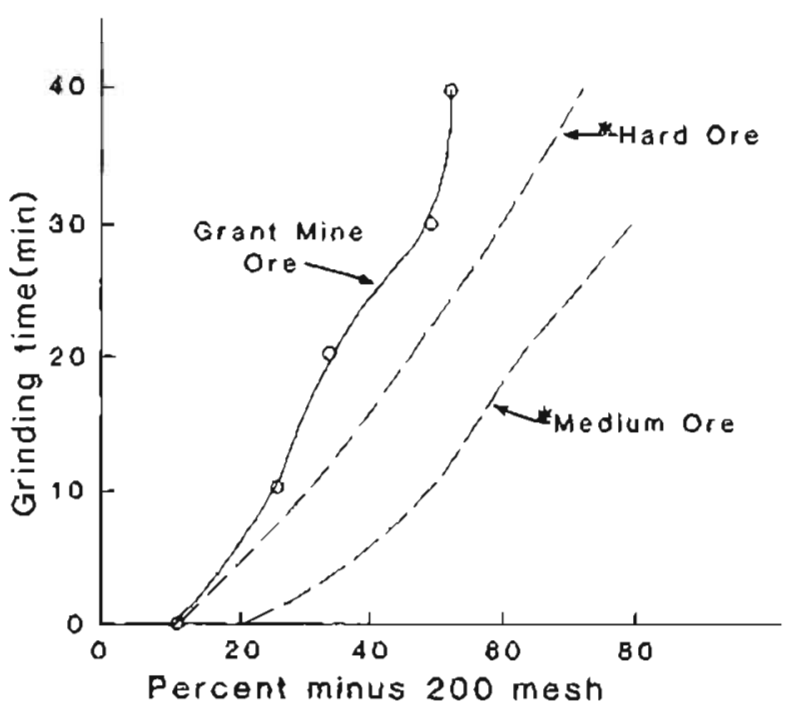

Figure 3. Graph comparing the grindabitity of Grant Gold Mine ore with a hard ore and a medium ore. (* . Standard provided by Denver Equipment. Co., Bulletin B2-B34A).

son, when entered into the Denver Equipment ball. mill slide rule, deternmes the size of ball mill that will be required to provide a specilic product given a particular fecd size to a ball nill (now sheel, p. 14). T'he screnen analysis and grinding tests are shown in tables 1 through 5 and ploted as ligure 2. Figure 3 compares Cirant Mine ore with a lypical hard and a medium-soft ore.

Gold is very malleable, and it will natten instead of pulverize in the ball mill. Overgxinding will result ill a loss of gold in a gravity (table) recovery.

Table 6 show's where the gold reports in the various size fractions. Note that the assay value of gold in the plus 100-mish.size fraction increases correspondingly

Table 1. Sicec analysio of ore reduced le munus 10 mesh in a rolis crusher.

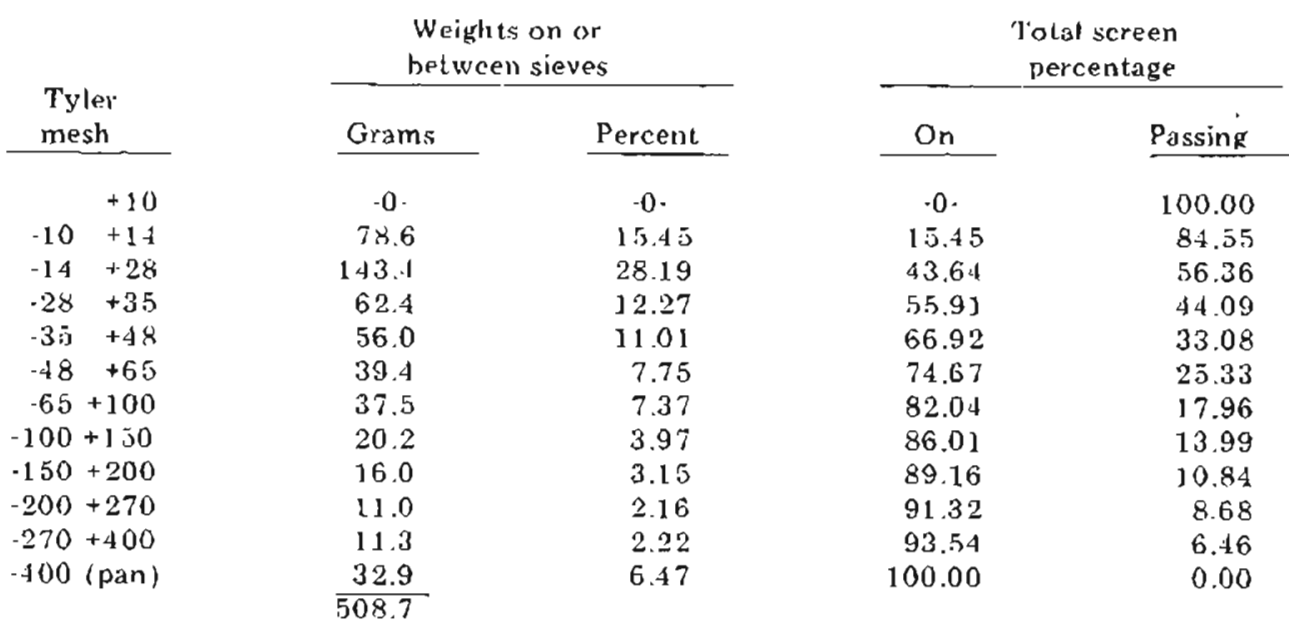


with the length of grinding, from 0.29 to $36.45 \mathrm{oz}$ iton. By plotting the cumulative percent of total gold in each size fraction (Lable 6 ), a noticeable break occurs between the 20- and 30-nin grinding times. II figure 2 , the curve displayed for 20 min of grinding flattens to a straight line after 30 min. Thus, liberation probably occurred at about 25 min of grinding time, or at about 98 percent minus 65 mesh.

\section{SINK-FLOAT SEPARA'TION}

Each mesh-size fraction was separated with the heavy liquid bromoform (specific gravity 2.86) into a sink product and a float product. Each product was then assayed for gold and silver. Table 7 shows the size fraction, weight, assay value, and percent recovered; table 8 provides similar information for silver on the same sample. Figure 4 illustrates the grind required to liberate gold and silver by plotting the assay value of

Table 2. Sifve andysis after $10 \mathrm{~min}$. of wel grinding.

Tyler

mesh

$+100$

$-100+200$

$-200+400$

-400 (Pan)

ryler mesli

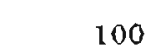

$-100+200$

$-200+400$

-400 (pan1)

Tyler mesh

100

$-100+200$

$-200+400$

-400 (pan)

Tyler mesh

100

$-100+200$

$-200+400$

.400 (pan)
Weights on or between sieves

\begin{tabular}{c}
\hline Grams \\
\hline 234.5 \\
84.19 \\
56.31 \\
127.50
\end{tabular}

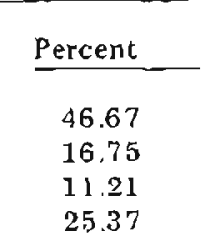

\begin{tabular}{|c|c|}
\hline On & Passing \\
\hline 46.67 & 53.33 \\
\hline 63.42 & 36.58 \\
\hline 74.63 & 25.37 \\
\hline 100.00 & 0 \\
\hline
\end{tabular}

Table 3. Sicve analysis afler 20 min. of wet grinding.

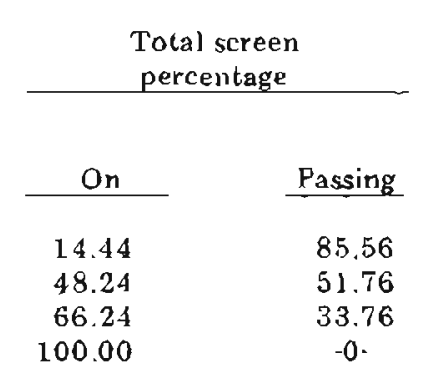

Table 4. Sieve onalysis after $30 \mathrm{~min}$. of wel grinding.
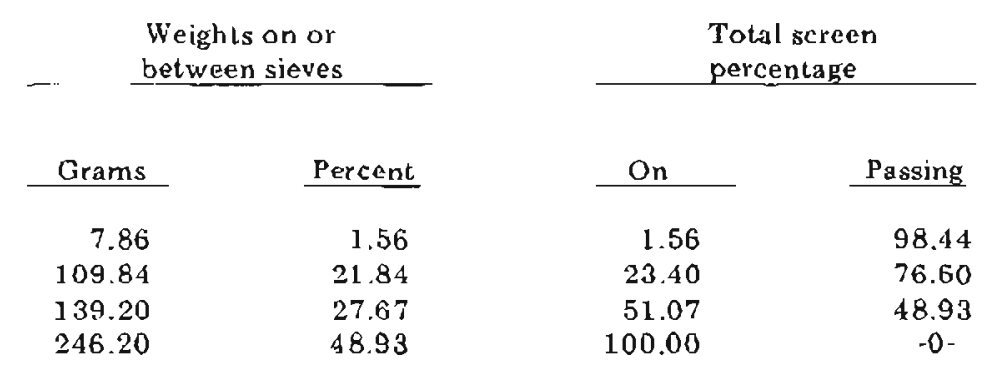

'Pable 5. Sieve analy'sis after $40 \mathrm{~min}$. of wet grinding.

\begin{tabular}{|c|c|}
\hline Grams & Percent \\
\hline 7.86 & 1.56 \\
\hline 109.84 & 21.84 \\
\hline $\begin{array}{l}139.20 \\
246.20\end{array}$ & $\begin{array}{l}27.67 \\
48.93\end{array}$ \\
\hline
\end{tabular}

Weights on or between sieves

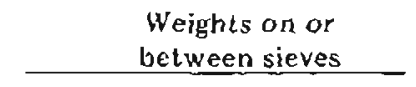

$\begin{array}{rr}\text { Grams } & \text { Percent } \\ 1.5 & \\ 101.7 & 0.30 \\ 134.9 & 20.28 \\ 262.7 & 26.88 \\ & 52.54\end{array}$

Total screen percentage

\begin{tabular}{|c|c|}
\hline On & Passing \\
\hline 0.30 & 99.70 \\
\hline 20.58 & 79.42 \\
\hline 47,46 & 52.54 \\
\hline 100.00 & -0 \\
\hline
\end{tabular}


the float fraction (tailings) and particle size. As shown in figure 5 , a plot of the percent of gold recovered versus particle size, a minus 65-mesh size is required for satisfactory recovery.

Similar information on sample 2 is contained in tables 9 and 10 and plotted as ligures 6 and 7 . The inter. pretation is similar, namely, that grinding to minus 65 mesh is required for optimum recoyery. 'The overall recovery on sample 1 was 68.33 percent for the gold; 71.92 percent was recovered in sample 2. This may indicate a slightly higher recovery on higher grade ore. The recovery of silver is lower.

In tables 7.10 (figures 6 and 7 ) inclusive, a decline in recovery is indicated, with an increase in value of the tails below 270 mesh. This is partly due to the difficulty in making a good separation in tine material. In a gravity recovery system, gold this time will be lost as a slime.

\section{AMALGAMATION}

In many instances, gold should be recovered by gravity separation or amalgamation (or both) before further treatment by cyasidation or flolation. Mc.
Quiston and Shoemaker $(1975$ ) report that the Dome Mine in Canada recovers about 55 percent of the gold by gravity and amalganation and another 42.4 percent by cyanidation, for a lotal recovery of 97.4 percent. Homestake Mining recovers from 20 to 25 percent by gravity and amalgamation; the rest of their total 94.6 to 95 percent recovery is obtained by cyanidation.

Hedley and 'Fabachnick (1968) report that "a researcher found the maximum rate of dissolution of gold by cyanide to be $3.25 \mathrm{mg} / \mathrm{cm}^{2} / \mathrm{hr}^{\text {." }}$ If so, much coarse gold (plus 65 mesh) might not be dissolved in a reasonable time, and the undissolved particles would go into the tailings. According to Glembotskii and others (1963). the maximum size of a gold spherical particle that can be foated is $0.2 \mathrm{~mm}$ or 65 mesh (Tyler). Removal of coarser gold by gravity or amalgamation before fotation or cyanidation will improve the overall recovery and prevent accumulation of gold in the bottom of the classifier or in the ball-mill scoop box.

Four amaigamation tests were completed: two each on samples 1 and 2 . In each test, about $0.5 \mathrm{~g}$ of inercury and water equal to 1.5 limes the sample weight $(1,000 \mathrm{~g})$ was added. Next, the sample was rotated in a barrel amalgamator in the laboratory for 2 hy and the

Table 6. Assay of value of liaclions and percent of lotal gold in each size fraction.

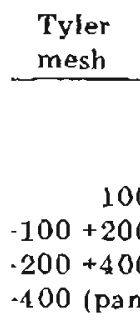

100

$100+200$

400 (pan)

100
$-100+200$

$-200+400$

-400 (pan)

100

$-100+200$

$-200+400$

400 (pan)

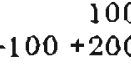

$-200+400$

400 (pan)

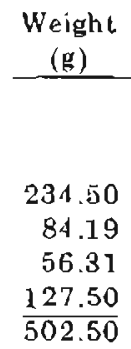

72.74

170.20

90.65

165.40

$\overline{499.99}$

7.79

109.84

139.20

246.20

$\overline{503.03}$

1.41

101.70

134.90

262.70

500.71

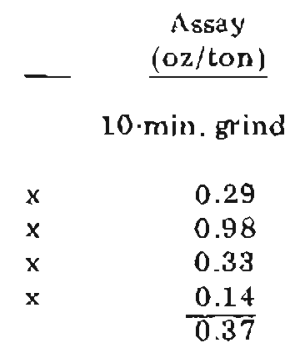

20-min, grind

$\mathrm{x}$
$\mathrm{x}$
$\mathrm{x}$

\begin{tabular}{l}
1.00 \\
0.57 \\
0.32 \\
0.14 \\
\hline 0.44
\end{tabular}

$=$

$=$

97.01

$=$

$=$

29.01

23.30

$\overline{222.06}$

30-min. grind

$x$
$x$
$x$
$x$

\begin{tabular}{l}
5.10 \\
0.52 \\
0.26 \\
0.15 \\
\hline 0.34
\end{tabular}

$=$

39.73

57.12

36.19

36.93

$\frac{36.93}{169.97}$

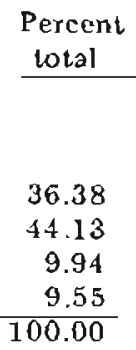

$40 \cdot \min$. grind

$\begin{array}{r}36.45 \\ 0.66 \\ 0.23 \\ 0.36 \\ \hline 0.49\end{array}$
$=$
$=$

51.39

67.12

31.03

94.57

$\frac{94.51}{244.11}$
32.76

43.69

13.06

10.49

100.00

23.37

33.51

21.29

21.73

$\frac{21.73}{100.00}$

21.05

27.50

12.71

38.74
10000 


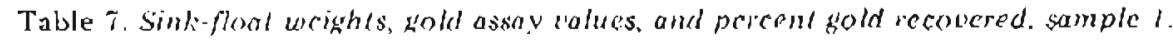

\begin{tabular}{|c|c|c|c|c|c|}
\hline \multicolumn{2}{|c|}{$\begin{array}{l}\text { Mesli-size } \\
\text { Iraction }\end{array}$} & \multirow{2}{*}{$\begin{array}{l}\text { Weight } \\
\frac{(\mathrm{g})}{71.7}\end{array}$} & \multirow{2}{*}{$\begin{array}{c}\begin{array}{c}\text { Percent } \\
\text { Lotal }\end{array} \\
14.7 \mathrm{~A}\end{array}$} & \multirow{2}{*}{$\frac{\begin{array}{c}A \sin y \\
\left(0 z^{\prime} \operatorname{ton}\right)^{c}\end{array}}{0.55}$} & \multirow[t]{2}{*}{$\begin{array}{l}\text { Percent } \\
\text { recovered }\end{array}$} \\
\hline & $+14 \mathrm{Fr}^{0}$ & & & & \\
\hline & $+14 S^{b}$ & 6.4 & 1.32 & 0.31 & 7.63 \\
\hline-14 & $+28 F$ & 128.5 & 26.42 & 0.30 & \\
\hline-14 & +285 & 14.2 & 2.92 & 1.88 & 40.92 \\
\hline .28 & $+35 E$ & $\therefore 2.9$ & 10.88 & 0.15 & \\
\hline .28 & $+35 s$ & 7.5 & 1.54 & 1.35 & 56.06 \\
\hline 35 & $+48 F$ & 38.8 & 7.98 & 0.06 & \\
\hline-35 & $+48 \mathrm{~S}$ & 6.0 & 1.23 & 2.79 & 87.78 \\
\hline .48 & $+65 \mathrm{~F}$ & 33.3 & 6.85 & 0.08 & \\
\hline-18 & $+65 S$ & 6.0 & 1.23 & 5.21 & 92.16 \\
\hline .65 & $+100 F$ & 33.7 & 6.93 & 0.08 & \\
\hline-65 & $+100 \mathrm{~S}$ & 5.9 & 1.21 & 21.68 & 97.59 \\
\hline-100 & $+150 \mathrm{~F}$ & 8.3 & 1.71 & 0.05 & \\
\hline-100 & $+150 \mathrm{~S}$ & 3.1 & 0.64 & 6.45 & 97.34 \\
\hline .150 & $+200 \mathrm{~F}$ & 13.6 & 2.80 & 0.04 & \\
\hline-150 & $+200 \mathrm{~s}$ & 2.1 & 0.43 & 9.23 & 97.25 \\
\hline .200 & $+270 \mathrm{~F}$ & 8.9 & 1.83 & 0.03 & \\
\hline-200 & $+270 \mathrm{~s}$ & 1.0 & 0.21 & 7.03 & 96.37 \\
\hline-270 & $+400 \mathrm{~F}$ & 8.9 & 1.8 .3 & 0.09 & \\
\hline-270 & $+400 \mathrm{~s}$ & 1.2 & $0.2 \bar{i}$ & 4.49 & 87.08 \\
\hline .100 & F & 29.5 & 6.06 & 0.16 & \\
\hline .400 & $S$ & $\begin{array}{r}4.9 \\
-\end{array}$ & 1.01 & 1.60 & 62.43 \\
\hline & 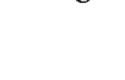 & 486.4 & $\overline{100.02}$ & $\begin{array}{c}0.64 \text { (weighted } \\
\text { avgs) }\end{array}$ & $\begin{array}{c}68.33 \text { (weighted } \\
\text { avg) }\end{array}$ \\
\hline
\end{tabular}

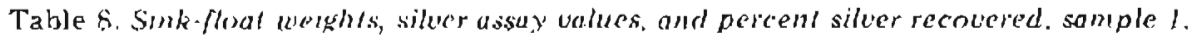

\begin{tabular}{|c|c|c|c|c|c|}
\hline \multicolumn{2}{|c|}{$\begin{array}{l}\text { Mesh size } \\
\text { [raction }\end{array}$} & \multirow{2}{*}{$\begin{array}{l}\text { Weight } \\
\frac{\text { (b) }}{71.7}\end{array}$} & \multirow{2}{*}{$\begin{array}{c}\begin{array}{c}\text { Percent } \\
\text { total }\end{array} \\
14.74\end{array}$} & \multirow{2}{*}{$\frac{\begin{array}{c}\text { Assay } \\
\text { (oz/ton) }\end{array}}{0.47}$} & \multirow[t]{2}{*}{$\begin{array}{l}\text { Percent } \\
\text { recuvered }\end{array}$} \\
\hline .10 & $+11 \mathrm{~F}$ & & & & \\
\hline-10 & $+14 S$ & 6.4 & 1.32 & 1.38 & 20.76 \\
\hline .14 & $+28 \mathrm{~F}$ & 128.5 & 26.42 & 0.32 & \\
\hline-14 & $+28 \mathrm{~S}$ & 14.2 & 2.92 & 2.23 & 43.51 \\
\hline 28 & $+35 \mathrm{~F}$ & 52.9 & 10.88 & 0.30 & \\
\hline .28 & $+35 s$ & 7.5 & 1.54 & 102 & 32.53 \\
\hline-35 & $+.18 \mathrm{~F}$ & 38.8 & 7.98 & 0.22 & \\
\hline-35 & $+48 \mathrm{~S}$ & 6.0 & 1.23 & 2.41 & 61.48 \\
\hline .48 & $+65 F$ & 33.3 & 6.85 & 0.23 & \\
\hline .48 & $+65 S$ & 6.0 & 1.33 & 3.70 & 74.35 \\
\hline-65 & $+100 \mathrm{~F}$ & 33.7 & 6.93 & 0.36 & \\
\hline .65 & 1005 & 5.9 & 1.21 & 0.75 & 26.75 \\
\hline-100 & $+150 F$ & 8.3 & 1.71 & 0.33 & \\
\hline .100 & $+150 \mathrm{~s}$ & 3.1 & 0.64 & $4.2]$ & 82.58 \\
\hline-150 & $+200 \mathrm{~F}$ & 13.6 & 2.80 & 0.25 & \\
\hline-150 & $+200 \mathrm{~S}$ & 2.1 & 0.43 & 5.88 & 78.41 \\
\hline-200 & $+270 \mathrm{~F}$ & 8.9 & 1,83 & 0.32 & \\
\hline-200 & $+270 \mathrm{~S}$ & 1.0 & 0.21 & 7.85 & 73.36 \\
\hline-270 & $+400 F$ & 8.9 & 1.83 & 0.65 & \\
\hline-270 & $+400 \mathrm{~S}$ & 1.2 & 0.25 & 9.74 & $69.9 \mathrm{~J}$ \\
\hline-400 & $\mathrm{~F}$ & 29.5 & 6.06 & 0.99 & \\
\hline .400 & $\mathrm{~S}$ & 4.9 & 101 & 3.56 & 37.38 \\
\hline & & 486.4 & 100.02 & $\begin{array}{c}0.6 .5 \text { (weighted } \\
\text { avg) }\end{array}$ & $\begin{array}{c}48.23 \text { (weighted } \\
\text { avg) }\end{array}$ \\
\hline
\end{tabular}


Table 9. Simk-fleat weikhts, gestl assay valurs. and percent fold recotered, sample 2.

\begin{tabular}{|c|c|c|c|c|c|}
\hline \multicolumn{2}{|c|}{$\begin{array}{l}\text { Mesh size } \\
\text { Praction }\end{array}$} & \multirow{2}{*}{$\begin{array}{l}\text { Weight } \\
\frac{(g)}{64.9}\end{array}$} & \multirow{2}{*}{$\begin{array}{c}\begin{array}{c}\text { Percent } \\
\text { total }\end{array} \\
13.07\end{array}$} & \multirow{2}{*}{$\frac{\begin{array}{c}\text { Assay } \\
\text { (oz/ton) }\end{array}}{1.95}$} & \multirow[t]{2}{*}{$\begin{array}{l}\text { Percent } \\
\text { recovered }\end{array}$} \\
\hline & +145 & & & & \\
\hline & +145 & 9.4 & 1.89 & 2.26 & 14.37 \\
\hline .14 & $+28 \mathrm{~F}$ & 150.1 & 30.23 & 1.81 & \\
\hline .14 & $+28 \mathrm{~S}$ & 24.0 & 4.83 & 4.19 & 27.01 \\
\hline .28 & $+35 \mathrm{~F}$ & 51.2 & $\mathrm{~L} 0.3 \mathrm{~L}$ & 1.14 & \\
\hline .28 & $+35 \mathrm{~S}$ & 10.3 & 2.07 & 3.01 & 34.69 \\
\hline-35 & $+48 \mathrm{~F}$ & 33.5 & 6.75 & 0.93 & \\
\hline .35 & $+48 \mathrm{~S}$ & 7.8 & 1.57 & 0.69 & 1472 \\
\hline-18 & $+65 \mathrm{~F}$ & 28.7 & 5.78 & 0.49 & \\
\hline .98 & $+65 \mathrm{~S}$ & 7.4 & 1.49 & 6.84 & 78.26 \\
\hline .65 & $+100 \mathrm{~F}$ & 21.0 & 1.23 & 0.15 & \\
\hline-65 & $+100 \mathrm{~s}$ & 5.9 & 1.19 & 8.78 & 94.26 \\
\hline-100 & $+150 \mathrm{~F}$ & 18.0 & 3.62 & 1.96 & \\
\hline-100 & $+150 \mathrm{~S}$ & 6.0 & 1.21 & 169.87 & 96.65 \\
\hline .150 & $+200 \mathrm{~F}$ & 14.6 & 2.94 & 0.14 & \\
\hline-150 & $+200 \mathrm{~S}$ & 3.7 & 0.75 & 22.79 & 97.63 \\
\hline-200 & $+270 \mathrm{~F}$ & 8.2 & 1.65 & 0.11 & \\
\hline-200 & $+270 \mathrm{~S}$ & 2.2 & 0.44 & 17.15 & 97.67 \\
\hline-270 & $+400 \mathrm{~F}$ & 3.4 & 1.49 & 0.35 & \\
\hline .270 & $+400 \mathrm{~S}$ & 2.1 & 0.42 & 11.86 & 90.59 \\
\hline-400 & $\mathrm{~F}$ & 19.7 & 3.97 & 0.70 & \\
\hline .400 & $S$ & 0.5 & 0.10 & 11.34 & 29.14 \\
\hline & & $4 \overline{49.5}$ & $1 \overline{00.00}$ & $\begin{array}{c}4.01 \text { (woighted } \\
\text { avg) }\end{array}$ & $\begin{array}{c}71.92 \text { (weighted } \\
\text { avg) }\end{array}$ \\
\hline
\end{tabular}

Tahle 10. Sint-fioul weights and silerer assay calues, sample 2.

\begin{tabular}{|c|c|c|c|c|}
\hline $\begin{array}{l}\text { Mesh size } \\
\text { Traction }\end{array}$ & $\begin{array}{l}\text { Weight } \\
\text { (g) }\end{array}$ & $\begin{array}{l}\text { Percent } \\
\text { total }\end{array}$ & $\begin{array}{l}\text { Assay } \\
\text { (oz/lon) }\end{array}$ & $\begin{array}{c}\text { Percent } \\
\text { recovered }\end{array}$ \\
\hline$-10+14 F$ & 64.9 & 13.07 & 0.89 & \\
\hline $.10+14 S$ & 9.4 & 1.89 & 1.55 & 20.14 \\
\hline$-\mathrm{L} 4+28 \mathrm{~F}$ & 150.1 & 30.23 & 1.19 & \\
\hline$-11+285$ & 24.0 & 4.83 & 2.31 & 23.69 \\
\hline$-28+35 \mathrm{k}$ & 51.2 & 10.31 & 0.51 & \\
\hline$-28+355$ & 10.3 & 2.07 & 1.60 & 38.69 \\
\hline$-35+48 \Gamma$ & 33.5 & 6.75 & 0.62 & \\
\hline$-35+48 s$ & 7.8 & 1.57 & 6.22 & 70.02 \\
\hline$-48+65 F$ & 28.7 & 5.78 & 0.33 & \\
\hline$-18+65 s$ & 7.4 & 1.49 & 3.08 & 70.06 \\
\hline$-65+100 F$ & 21.0 & 4.23 & 0.40 & \\
\hline$-65+100 \mathrm{~s}$ & 5.9 & 1.19 & 4.29 & 75.08 \\
\hline$-100+150 F$ & 18.0 & 3.62 & 1.24 & \\
\hline$-100+150 \mathrm{~s}$ & 6.0 & 1.21 & 32.11 & 89.62 \\
\hline$-150+200 \mathrm{~F}$ & 14.6 & 2.94 & 0.12 & \\
\hline$-150+200 \mathrm{~s}$ & 3.7 & 0.75 & 9.11 & 95.06 \\
\hline$-200+270 \mathrm{~F}$ & 8.2 & 1.65 & 0.49 & \\
\hline$-200+270 \mathrm{~S}$ & 2.2 & 0.44 & 6.70 & 78.57 \\
\hline $.200+400 \mathrm{~F}$ & 7.4 & 1.49 & 1.01 & \\
\hline$-200+400 \mathrm{~S}$ & $2 . x$ & 0.42 & 7.50 & 67.83 \\
\hline $.400 \quad F$ & 19.7 & 3.97 & 1.85 & \\
\hline .400 & $\frac{0.5}{496.9}$ & $\frac{0.10}{100.00}$ & $\frac{21.60}{0.64(a v g)}$ & $\frac{22.86}{54.81 \text { (avg }}$ \\
\hline
\end{tabular}




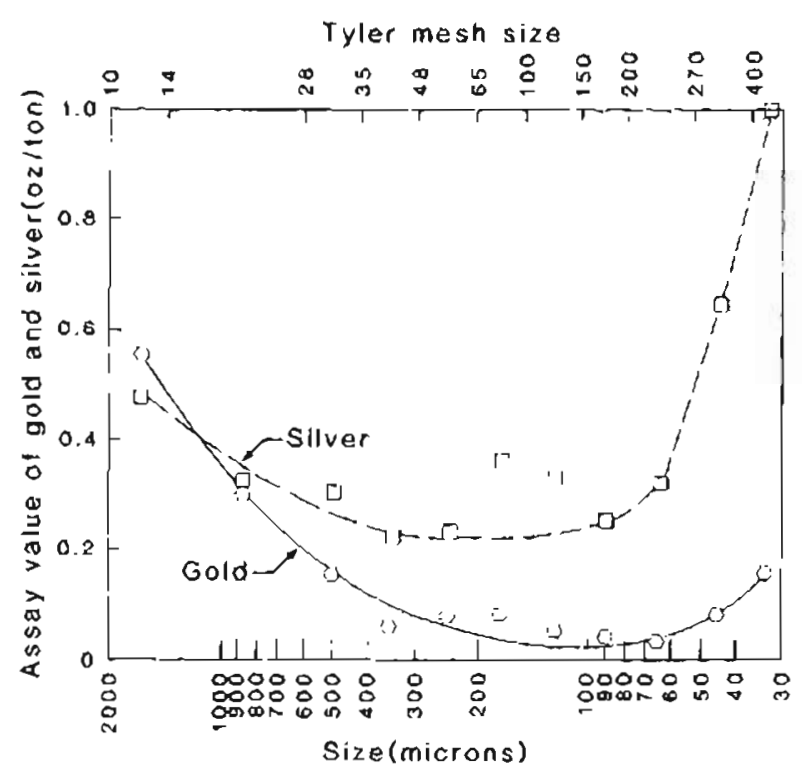

Figure A. Gold and silver values of the lloat fraction (tails) lor each size fraction, heavy-liquid separa. lions, 2.86 syecific gravily, simple 1.

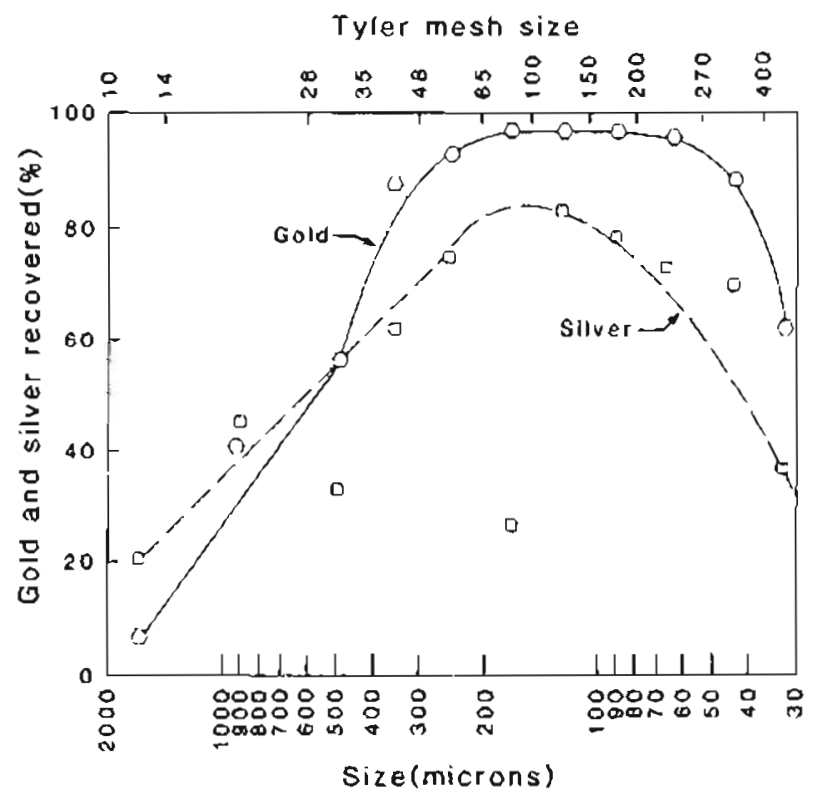

Figure 5. Percent of gold and silver recavered in the sink fraction (concentrate) for each size fraction, heavy-liquid separation, 2.86 specific gravity, sample 1.

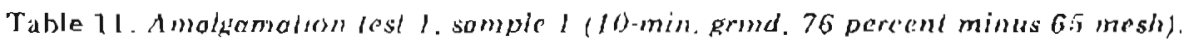

\begin{tabular}{|c|c|c|c|c|}
\hline & $\begin{array}{c}\text { Goldl } \\
(02 / \operatorname{con})\end{array}$ & Percent & $\begin{array}{c}\text { Silver } \\
\text { (oz/ton) }\end{array}$ & Percent \\
\hline Heads & 0.34 & 100 & 0.54 & 100 \\
\hline Recuvered & 0.25 & 73.5 & 0.18 & 32.5 \\
\hline Tails & 0.09 & 26.5 & 0.36 & 67.5 \\
\hline
\end{tabular}

Table 12. Amalsamation lest 2, sample I (20)-min. grind, 88 percent minus 65 mesh).

\begin{tabular}{|c|c|c|c|c|}
\hline & $\begin{array}{c}\text { Gold } \\
(0 \% \text { inn })\end{array}$ & Percent & $\begin{array}{c}\text { Silver } \\
\text { (oz/ton })\end{array}$ & Percent \\
\hline Heads & 0.45 & 100 & 0.57 & 100 \\
\hline Recovered & 0.31 & 68.9 & 0.09 & 15.8 \\
\hline Tails & 0.14 & 31.1 & 0.48 & 84.2 \\
\hline
\end{tabular}

Table 13. Amalgamation test 3, sample 2 (10-min. grind, 76 percent minus 65 mesh)

\begin{tabular}{|c|c|c|c|c|}
\hline & $\begin{array}{c}\text { Gold } \\
\text { (oz/ton) }\end{array}$ & Percent & $\begin{array}{l}\text { Silver } \\
\text { (oz/ton) }\end{array}$ & Percent \\
\hline Heads & 2.04 & 100 & 1.15 & 100 \\
\hline Recovered & 1.57 & 76.8 & 0.31 & 27.0 \\
\hline Tails & 0.47 & 23.2 & 0.84 & 73.0 \\
\hline
\end{tabular}

Table 14. Amalganalion lest 4, sample 2 (20)-min, grind, 88 percent minus 65 mesh).

\begin{tabular}{|c|c|c|c|c|}
\hline & $\begin{array}{c}\text { Gold } \\
(\text { az/lon) }\end{array}$ & Percent & $\begin{array}{l}\text { Silver } \\
\text { (oz/ton) }\end{array}$ & Percent \\
\hline Hearls & 2.03 & 100 & 0.77 & 100 \\
\hline Recovered & 1.84 & 90.6 & 0.22 & 28.6 \\
\hline Tails & 0.19 & 9.4 & 0.55 & 71.4 \\
\hline
\end{tabular}




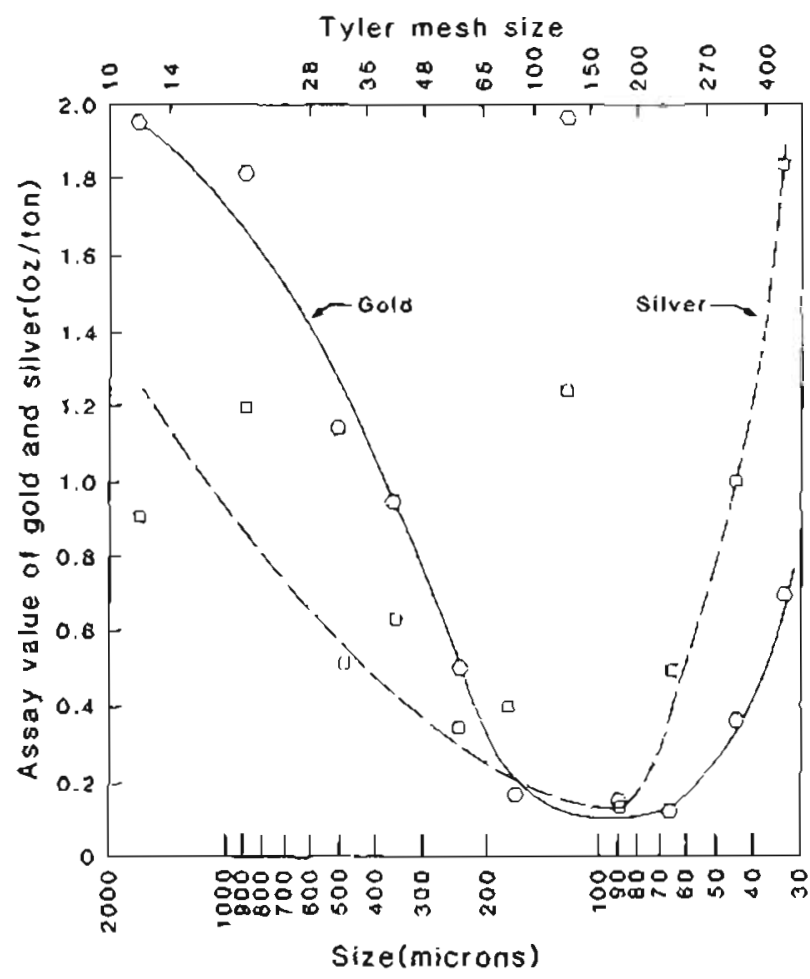

Figure 6. Goid and silver values of Moat fractions from sink-Moat separations (Lajls), sample 2.

amalgam was recovered by panning. The mercury was then removed by dissolving in ritric acid. The gold was annealed, weighed, and parted to determine the amount of silver present (tables 11-14).

About 70 percent of the gold was recovered in somple 1. In sample 2 (amalgamation test 4), 90.6 percent gold was extracted. Only the silver alloyed with gold was recovered by amalgamation; the siber recovery was low, 15 to 32 percent.

\section{FLOTATION}

Precious metals may be recovered by flotation to produce a high grade concentrate for direct sale to a smeiter or as a pretreatment for a cyanidation plant. Refractory ores such as those containing arsenic, a cyanicide. require roasting. Concentrating ores by fotation permits reducing the size of the roasting and cyanidation plant. Woolf and Jackson (1939) reported that fotation, roasting, and cyanidation al the Getchel Mine in Nevada increased recovery of gold from 52.7 percent to over 90 percent; at the Maitland Mine, also in Nevada, recovery increased from 28.15 to 90.3 percent with the same methods.

Six Ratation tests were completed, two with tle coarse gold removed by amalgamation and four without. In each test the following reagents were used: Aeronoat-208 (sodium diethyl and sodium di-secondary

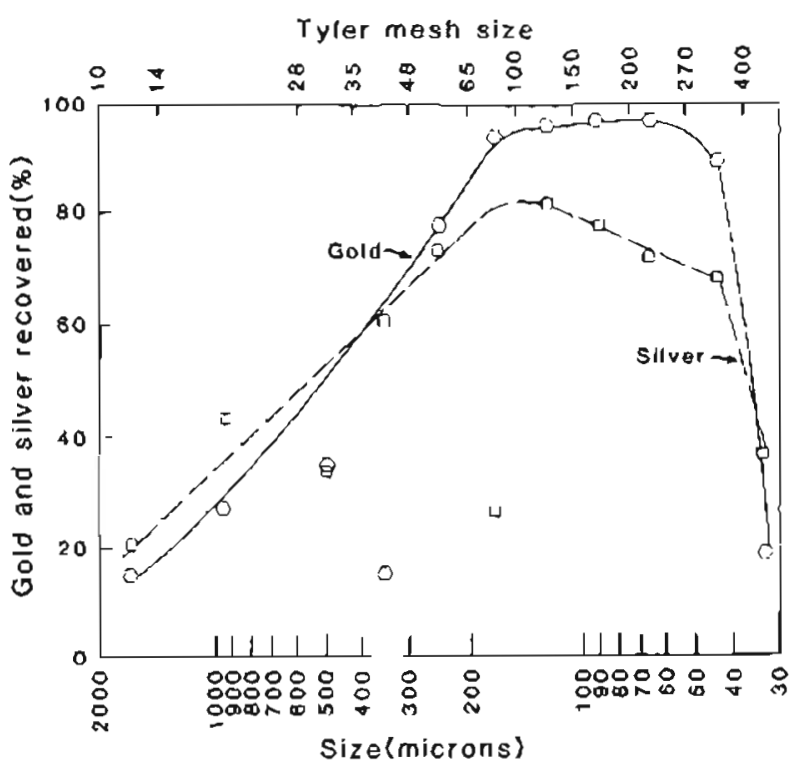

Figure 7 . Percent of gold and silver recovered in each sink-size fraction from sink-float heavy-likuid separations, sample 2.

butyl dithiophospliate), 0.1 loiton: Aeroxanthate. 301 (sodium secondary butyl xanthate), $0.1 \mathrm{lb}$ /ton: and Dow froth 250.0.1 lbiton ( $\mathrm{pH} \mathrm{6.8-8).} \mathrm{The} \mathrm{mixing}$ time was $10 \mathrm{~min}$ and flotation time was 5 min (tables 15.20).

In short, the flotation tesis without pretreatment recovered 95 percent of the gold and 60 percent of the silver in a concentrate averaging 7.55 oziton gold and 5.40 oziton silver with a concentration ratio of about 18:1. Although no effort was made to depress the arsenopyrite, most of the arsenic remained in the tails. and the concentrate had only 0.03 percent arsenic. versus 0.48 percent in the heads.

In fotalion tests 1 and 2 , where 73.5 and 68.9 percent of the gold was removed by amalgamation (cables 12 and 13), 58.2 and 56.2 percent of the remaining gold was recovered, respectively. This computes to an extraction of 88.9 percent with pretreatment versus 95 percent wichout. Silver recovery increased from 60 percent to 65.4 percent, and thus appears to have been slightly improved by pretreatment.

\section{CYANIDATION}

Cyanidation alone may be used to recover gold and silver or it may be used as a posttreatment to gravity, amalgamation, or flotation. The cyanide salts of sodium, potassium, or calcium in very dilute solutions ( $1 \mathrm{lb}$ of cyanide salt per ton of ore) dissolve the two precious metals. The solution must have a free inetal face for the chemical to attack with (preferably) no cyanicides--copper, zinc, or arsenic minerals--present in the ore. However, if cyanicides are present, 


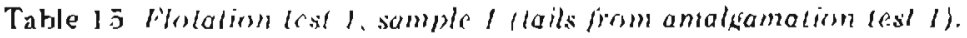

\begin{tabular}{|c|c|c|c|c|c|}
\hline & $\begin{array}{c}\text { Weiglit } \\
\text { (y) }\end{array}$ & $\begin{array}{c}\text { Gotd } \\
\operatorname{loz} / \operatorname{lon}(1)\end{array}$ & Percent & $\begin{array}{c}\text { Silver } \\
\text { (oz/ton) }\end{array}$ & Percent \\
\hline Headie & 839 & 0.09 & 100.0 & 0.36 & 100.0 \\
\hline Flotation conc. & 76 & 0.56 & 58.2 & 2.17 & $5+.6$ \\
\hline Tails & 763 & 0.04 & +1.8 & 0.18 & 45.3 \\
\hline $\begin{array}{l}\text { Total recovery } \\
\text { (amalgamation } \\
\text { plus folation) }\end{array}$ & & & 87.0 & & 66.8 \\
\hline
\end{tabular}

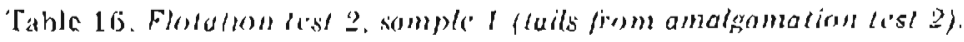

\begin{tabular}{|c|c|c|c|c|c|}
\hline & $\begin{array}{c}\text { Weight } \\
\text { (g) } \\
\end{array}$ & $\begin{array}{c}\text { Gold } \\
\text { (oxjton) }\end{array}$ & Precent & $\begin{array}{c}\text { Silver } \\
\text { (az/ton) }\end{array}$ & Percent \\
\hline Heads & 895 & 0.11 & 100.0 & 0.48 & 100.0 \\
\hline Flotation conc. & 110 & 0.64 & 56.2 & 2.12 & 54.3 \\
\hline Tails & 785 & 0.07 & .13 .8 & 0.25 & 45.7 \\
\hline $\begin{array}{l}\text { Total recovery } \\
\text { (amalgamation } \\
\text { plus Motation) }\end{array}$ & & & 88.8 & & 66.9 \\
\hline
\end{tabular}

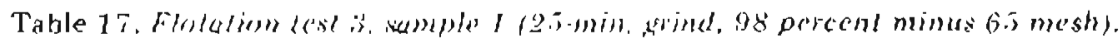

\begin{tabular}{|c|c|c|c|c|c|}
\hline & $\begin{array}{c}\text { Weight } \\
\text { (g) }\end{array}$ & $\begin{array}{c}\text { Gold } \\
\text { loz/coni }\end{array}$ & Percent & $\begin{array}{c}\text { Silver } \\
\text { (oziton) }\end{array}$ & Percent \\
\hline Heads & 503 & $0.4 \lambda$ & 100.0 & 0.23 & 100.0 \\
\hline Flotation conc. & 23 & 8.34 & 92.9 & 1.72 & 35.1 \\
\hline Tails & 488 & 0.03 & 7,1 & 0.15 & 64.9 \\
\hline
\end{tabular}

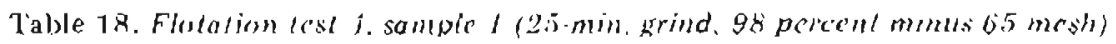
duphation of tesi 3 .

\begin{tabular}{|c|c|c|c|c|c|}
\hline & $\begin{array}{c}\text { Weight } \\
\text { (g) }\end{array}$ & $\begin{array}{c}\text { Gold } \\
\text { (oz/ton) }\end{array}$ & Percent & $\begin{array}{c}\text { Silver } \\
(\text { oz/ton })\end{array}$ & Percent \\
\hline Heads & 520.5 & 0.35 & 100.0 & 0.26 & 100.0 \\
\hline Flotation conc. & 6.5 .2 & 2.62 & 94.9 & 1.13 & 55.5 \\
\hline Tails & 455.3 & 0.02 & 5.1 & 0.13 & +4.5 \\
\hline
\end{tabular}

Table 19. Flelation lest 5. sample I (-55-mim, srind. 98 percend mindes 65 mesh).

\begin{tabular}{|c|c|c|c|c|c|c|}
\hline & $\begin{array}{l}\text { Weight } \\
(g)\end{array}$ & $\begin{array}{c}\text { Gold } \\
\text { \{ozítonl } \\
\end{array}$ & Percent & $\begin{array}{c}\text { Silver } \\
(\mathrm{c} \pi / \text { ton })\end{array}$ & Percent & Arsenic $(\%)$ \\
\hline Heads & 489.82 & 0.52 & 100.0 & 0.60 & 1000 & 0.48 \\
\hline Flotation conc. & 27.82 & 8.76 & 96.1 & 7.85 & 71.7 & 0.03 \\
\hline Tails & 162.0 & 0.02 & 3.6 & 0.16 & 25.3 & 0.51 \\
\hline
\end{tabular}

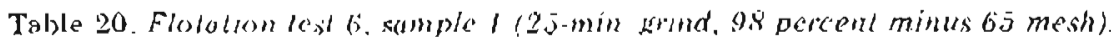

\begin{tabular}{|c|c|c|c|c|c|c|}
\hline & $\begin{array}{c}\text { Weight } \\
(\underline{g}) \\
\end{array}$ & $\begin{array}{c}\text { Gold } \\
\text { (oz/ton) }\end{array}$ & Percent & $\begin{array}{c}\text { Silver } \\
(02 / \text { lon }) \\
\end{array}$ & Percent & Arsenic (Fo) \\
\hline Heads & 484.2 & 0.42 & 100.0 & 0.58 & 100.0 & 0.47 \\
\hline Flotation conc. & 19.2 & 10.48 & 95.6 & 10.90 & 75.0 & 0.03 \\
\hline 'Tails & 46.50 & 0.02 & 4.4 & 0.15 & 25.0 & 0.48 \\
\hline
\end{tabular}


either pretreatment (including roasting) or excessive amounts of cyanide (up to $16 \mathrm{lb}$ iton) may be required, as at Benquet, in the Phillipine Islands (McQuiston and Shoemaker. 1975). The precinus metals are recovered by precipitation with zinc dust or by absorption on charcoal. 2'ests are required to determine if the ore is amenable to cyanidation. reagent consumption, and grinding. Crushing and heap leaching can somelimes generale a fair recovery (Potter, 1969).

ln the first set of five tests, a $500 \mathrm{~g}$ sample was treated in a 1,000 -g solution of 0.05 percent potassium cyanide (KCN) buffered wilh eitluer $0.5 \mathrm{~g}$ calcium oxide (CaO) or $1 \mathrm{lb} \mathrm{KCN}$ and $1 \mathrm{lb}$ lime per ton of ore (1.ables $21.25)$. The tests indicate a peak and then a continual decline in recovery with finer grinding ( $\mathrm{fig} .8$ ).

Arsenic is present in the ore. Hedley and 'Pabachnick (1968) state, "The inhibiting effects of the sulfide compounds resulting from the decomposition of arsenic or antimony sulfide minerals is a surface phenomenon. These compounds or their ions are atlaclied to the gold surfaces, and inceraction of the gold, the oxygen, and the $\mathrm{CN}$ ions is partially prevented."

In the absence of arsenic and antimony sulfides (cyanicides). finer grinuing could be expected to im.

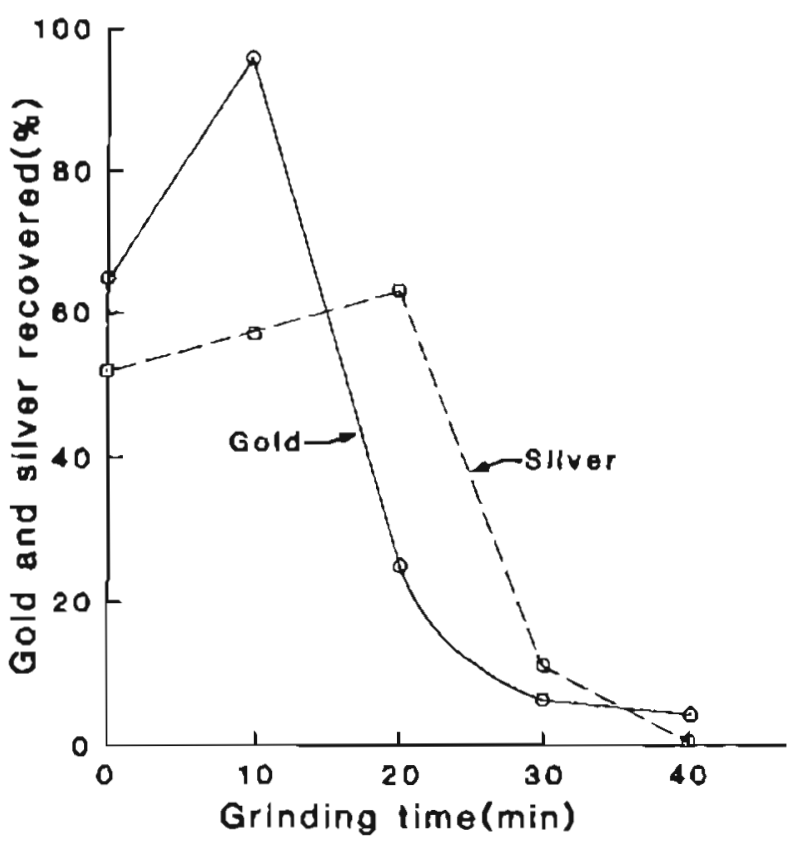

Figure 8. Elfect of particle size on the recovery of gold and silver by cyanidation. Dissolution time, $24 \mathrm{hr}$.

Table 21. C'ranidation dost 1 , sampld I (no grimding minus 10 mesh, $p H=9.3$ ).

\begin{tabular}{|c|c|c|c|c|c|}
\hline & $\begin{array}{l}\text { Gold } \\
\text { (o/fon })\end{array}$ & Percent & $\begin{array}{c}\text { Silver } \\
(0 z / 101))\end{array}$ & Percenl & $\begin{array}{c}\text { KCN consumed } \\
\text { (lb/ton) }\end{array}$ \\
\hline Heads & 0.48 & 100.0 & 0.60 & 100.0 & 0.81 \\
\hline Recovered & 0.31 & 64.6 & 0.31 & 51.7 & \\
\hline Tails & 0.17 & 35.1 & 0.29 & 48.3 & \\
\hline
\end{tabular}

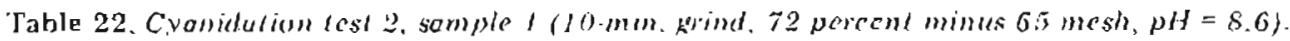

\begin{tabular}{|c|c|c|c|c|c|}
\hline & $\begin{array}{l}\text { Gold } \\
(\text { cos/ton })\end{array}$ & Percent & $\begin{array}{l}\text { Silver } \\
\text { (c)/lon) }\end{array}$ & Percent & $\begin{array}{c}\mathrm{KCN} \text { consumed } \\
(\mathrm{lb} / \mathrm{tan})\end{array}$ \\
\hline Hearis & 0.59 & 100.0 & 0.77 & 100.0 & 0.90 \\
\hline Recovered & 0.57 & 96.61 & 0.43 & う5.84 & \\
\hline T'ails & 0.02 & 3.39 & 0.31 & 44.16 & \\
\hline
\end{tabular}

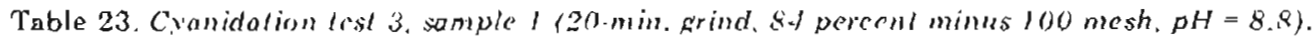

\begin{tabular}{|c|c|c|c|c|c|}
\hline & $\begin{array}{c}\text { Goid } \\
\text { (oz/Lon })\end{array}$ & Percent & $\begin{array}{l}\text { Silver } \\
\text { (oz/ton) }\end{array}$ & Percent & $\begin{array}{c}\mathrm{KCN} \text { consumed } \\
(\mathrm{lb} / \mathrm{ton})\end{array}$ \\
\hline Heads & 0.47 & 100.0 & 0.51 & 100.0 & 0.92 \\
\hline Recovered & 0.12 & 25.53 & 0.32 & 62.75 & \\
\hline Tnils & 0.35 & 74.17 & 0.17 & 37.25 & \\
\hline
\end{tabular}

Table 24. Cranide lest t. sample l (30-min. grind, of percent minus 100 mesh, $p H=8.8)$.

\begin{tabular}{|c|c|c|c|c|c|}
\hline & $\begin{array}{c}\text { Gold } \\
\text { (oz/ton })\end{array}$ & Percent & $\begin{array}{l}\text { Silver } \\
(02 / \text { ton })\end{array}$ & Percent & $\begin{array}{c}\mathrm{KCN} \text { consumed } \\
(\mathrm{lb} / \mathrm{ton})\end{array}$ \\
\hline Heads & 0.35 & 100.0 & 0.39 & 100.0 & 0.94 \\
\hline Recovered & 0.02 & 5.71 & 0.04 & 10.26 & \\
\hline Tails & 0.33 & 94.29 & 0,35 & 89.74 & \\
\hline
\end{tabular}




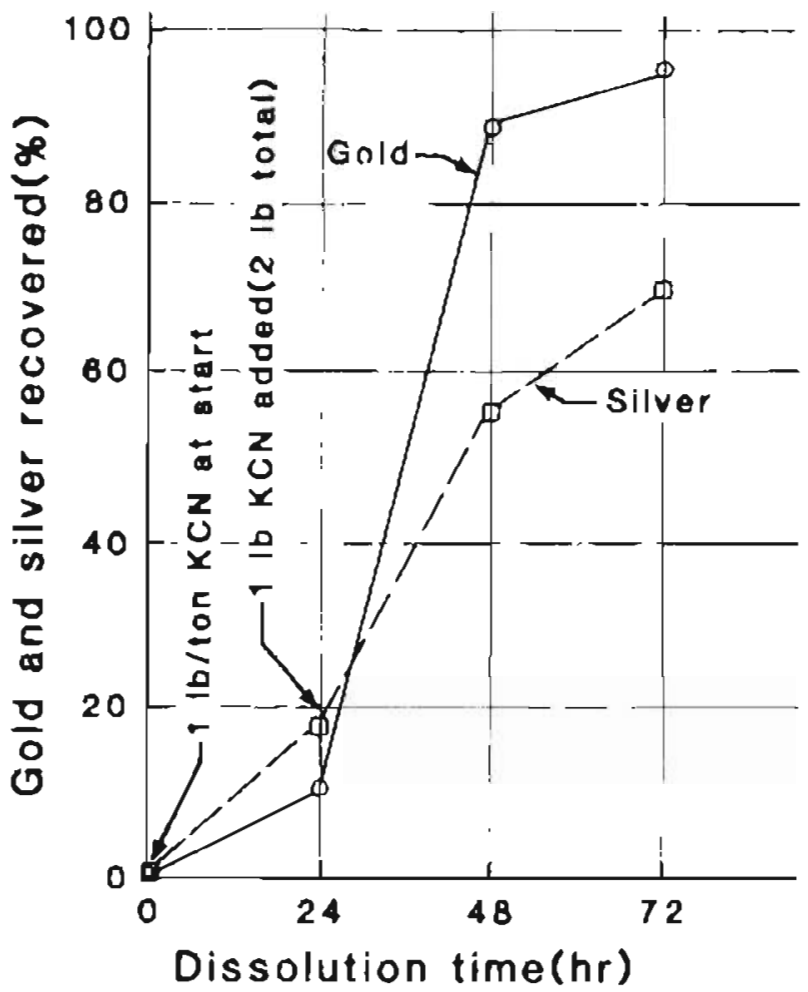

Figure 9. Elfect of dissolution tine and addition of cyanide on the recovery or grold and silver. Grinding lime, 25 min. prove the efficiency of cyanidation by increased liberation of gold. However. with cyanicides present, finer grinding increases the surface area of the sulticles and causes them to consume cyanide and thus limit the cx. traction of gold. In these lest.s, cyanide was consumed and recovery decreased will finer grinding. Because the cyanide was consumed, recovery might be increased by adding more cyanide and exterding the contact time. 'Test 6 was compleled thusly, with more cyanide plus lead nitrate and a longer contact time (cable 26. 6ig. 9).

Cyanide lests 7 and 8 (tables 27 and 28) wore conducted to determine the effect of extracting gold from a Motation concentrate and the value, if any, of calcining (roasting) the concentrate. The lests indicate that roasting resulted in a lower gold recovery and an abysmal silver recovery. Cyanide consumption was lowered. Additional testing should concentrate on the use of a stronger cyanide solution, additional relention time, and possibly grinding the calcine prior lo cyanida. tion. 'The overall recovery ol' gold by notation and cyanidalion was 88.5 percent; with roasting, 71.7 perceril.

fwo additional cyanide tests were completed on the tailings from amalyamalion lasts 3 and 4 (Lables 29 and 30). Cyanidation ol tailings rrom the amalgamation tests improved recovery of gold as shown in table 30 , where 99 perceint of the hold was extracted.

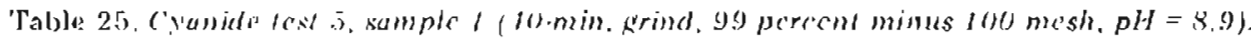

\begin{tabular}{|c|c|c|c|c|c|}
\hline & $\begin{array}{c}\text { Gold } \\
(0 \% / \text { lon })\end{array}$ & Percent & $\begin{array}{c}\text { Silver } \\
\text { (on/ton) }\end{array}$ & Percent & $\begin{array}{l}\text { KCN consumed } \\
\text { (lb/ton) }\end{array}$ \\
\hline Heads & 0.73 & 100.0 & 0.28 & 100.0 & 0.96 \\
\hline Recovered & 0.03 & I. & 0.00 & 0 & \\
\hline 'Гails & 0.70 & 95.89 & 0.28 & 100.0 & \\
\hline
\end{tabular}

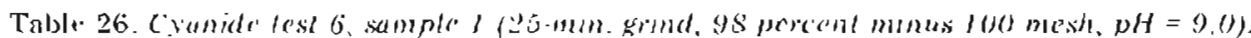

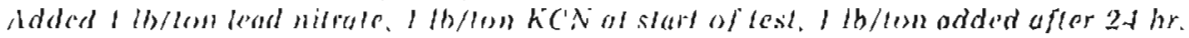

\begin{tabular}{|c|c|c|c|c|c|c|}
\hline & $\begin{array}{l}\text { Time } \\
\text { (hr) }\end{array}$ & $\begin{array}{c}\text { Ciold } \\
\text { (lb/lon) } \\
\end{array}$ & Prrcent & $\begin{array}{c}\text { Silver } \\
\text { (on/lon) }\end{array}$ & Percent & $\begin{array}{c}\text { KCN consumerl } \\
\text { (Ib/lon) }\end{array}$ \\
\hline Ileads & & 0.45 & 100.0 & 0.56 & 100.0 & \\
\hline Recovered & 24 & 0.05 & 11.1 & 010 & 17.86 & 0.95 \\
\hline Recovered & 48 & 0.40 & 89.0 & 031 & 55.4 & 1.76 \\
\hline Recovered & 72 & 0.43 & 95.6 & 0.39 & 69.6 & 1.94 \\
\hline Tails & & 0.02 & 4.4 & 0.17 & 30.4 & \\
\hline
\end{tabular}

Table 27. C'anlde lest 7. Holation concentrate (flotalton lest $5, \mathrm{pH}=12.0$ ).

\begin{tabular}{|c|c|c|c|c|c|}
\hline & $\begin{array}{c}\text { Gold } \\
\text { (oziton) }\end{array}$ & Percent & $\begin{array}{c}\text { Silver } \\
\text { (oz/ton) }\end{array}$ & Percent & $\begin{array}{c}\text { KCN consumed } \\
\text { (Ib/lon) }\end{array}$ \\
\hline Heads & 8.76 & 100.0 & 7.85 & 100.0 & \\
\hline Recoveredl & 8.04 & 91.8 & 6.31 & 80.4 & 0.76 \\
\hline 'Tajls & 0.72 & 8.2 & 1.54 & 19.6 & \\
\hline
\end{tabular}


Table 28. Cyanido lest 8. Molation concentrate. Fleslation lest 6 (coulcentrate roasted al $6.50^{\prime \prime} \mathrm{C}$ for $6 \mathrm{hr}, \mathrm{pH}=1 \mathrm{~g}$ ).

\begin{tabular}{|c|c|c|c|c|c|}
\hline & $\begin{array}{c}\text { Golkl } \\
\text { (oz/ton) }\end{array}$ & Percent & $\begin{array}{c}\text { Silver } \\
\text { (ozilon) }\end{array}$ & Percent & $\begin{array}{c}\text { KCN consumed } \\
(\mathrm{Ih} / \text { tom })\end{array}$ \\
\hline Heads & 10.48 & 100.0 & 10.90 & 100.0 & \\
\hline Recovered & 7.86 & 75.0 & 3.48 & 31.9 & 0.01 \\
\hline Tails & 2.62 & 25.0 & 7.42 & 68.1 & \\
\hline
\end{tabular}

Table 29. Cranide lest 9 (tailings from amalgamalion (cst $3, p H=3.4$ ).

\begin{tabular}{|c|c|c|c|c|c|}
\hline & $\begin{array}{l}\text { Gold } \\
\text { (oz/ton) }\end{array}$ & Percent & $\begin{array}{c}\text { Silver } \\
(\mathrm{oz} / \mathrm{ton})\end{array}$ & Percent & $\begin{array}{c}\text { KCN consumed } \\
\text { (lb/ton) }\end{array}$ \\
\hline Heads & 0.17 & 100.0 & 0.84 & 100.0 & \\
\hline Recavered & 0.35 & $7.4 . \hat{3}$ & 0.44 & 52.4 & 0.74 \\
\hline $\begin{array}{l}\text { Tails } \\
\text { Tolal recos }\end{array}$ & 0.12 & 25.5 & 0.40 & $\frac{47.6}{47.9}$ & \\
\hline
\end{tabular}

Table 30. Cranide iest 10 (lalls frumi amalkamaliun lest $f, p H=9.3$ ).

\begin{tabular}{|c|c|c|c|c|c|}
\hline & $\begin{array}{c}\text { Gold } \\
\text { (oz/ton) }\end{array}$ & Percent & $\begin{array}{c}\text { Silver } \\
\text { (oz/lon) }\end{array}$ & Percent & $\begin{array}{c}\mathrm{KCN} \text { consumed } \\
(\mathrm{lb} / \mathrm{Lon})\end{array}$ \\
\hline Heads & 0.19 & 100.0 & 0.55 & 100.0 & \\
\hline Recovered & 0.17 & 89.5 & 0.36 & 65.5 & 0.76 \\
\hline $\begin{array}{l}\text { Tails } \\
\text { 'Yotal rect }\end{array}$ & 0.02 & $-\frac{10.5}{990}$ & 0.19 & 34.5 & \\
\hline
\end{tabular}

\section{RECOVERY SLMMARY}

a. Ore froin the Cirant Mine is classilited as a 'hard ore' to grind.

J. Grinding to minus 65 mesh ( 210 microns) is required to liherate the gold.

c. The curves of sink floal fractions indicate that a 65 to 75 percent recovery of gold might be expected in gravily (table) recovery system at a minus 48-mesh grind.

d. Recovery by amalgamation varied from 68.9 to 90.6 percent.

e. Flolation of mine-run ore averaged 95 percent recovery of gold and 60 percent recovery of the silver. The overall recovery by flotation of amalgamation tailings was lower than wilh untreated ore.

f. An excollent recovery was made by cyanida. lion of mine-run ore ground to 72 percent minus 65 mesh. Additional grinding lowered recovery. The addition of cyanide wilh lead nitrate improved recovery.

g. The best overall recovery was obtained by cyanidation of the tails from sample 2 after removal of gold by ainalgamation: 99 percent of the gold and 75 percent of the silver.

\section{FLOW SHEET}

Figure 10 is a suggested now sheel for a llotation concentrator with a cyanidation circuit to produce a gold-silver bullion. 'l'he now sheet does not sliow all of the pumps that would be required, nor does it include a stripping section for recovery of gold and silver from the charcoal. In designing the llow slleet, the following criteria were used:

\section{a) For crushimg and grinding:}

1) A sizereduction ratio of $4: 1$ was used. A 10 - by $16-i n$. crusher call reduce $8 \mathrm{in}$. rock to 2 in. at 12 to 18 tons/hr. A 20-in. gyratory crusher has a similar capacity in reducing 2 -in. rock to minus $1 / 2$ II. 'This combination is admittedly overdesigned for 50 tons/day, but il is considered preferable $w$ smaller crusbers, where sticking of ore might be a yroblem. If the mill were increased to 100 tpd, no increase in size of the crushing plant. would be required for one shifl/day operatlon).

2) The ore is considered a hard one to grind (fig. 3). A 5 . by $5 . \mathrm{ft}$ ball mill will be required to grind 50 tons per 24 hr from minus $1 / 2$ in. to minus 65 mesh. 


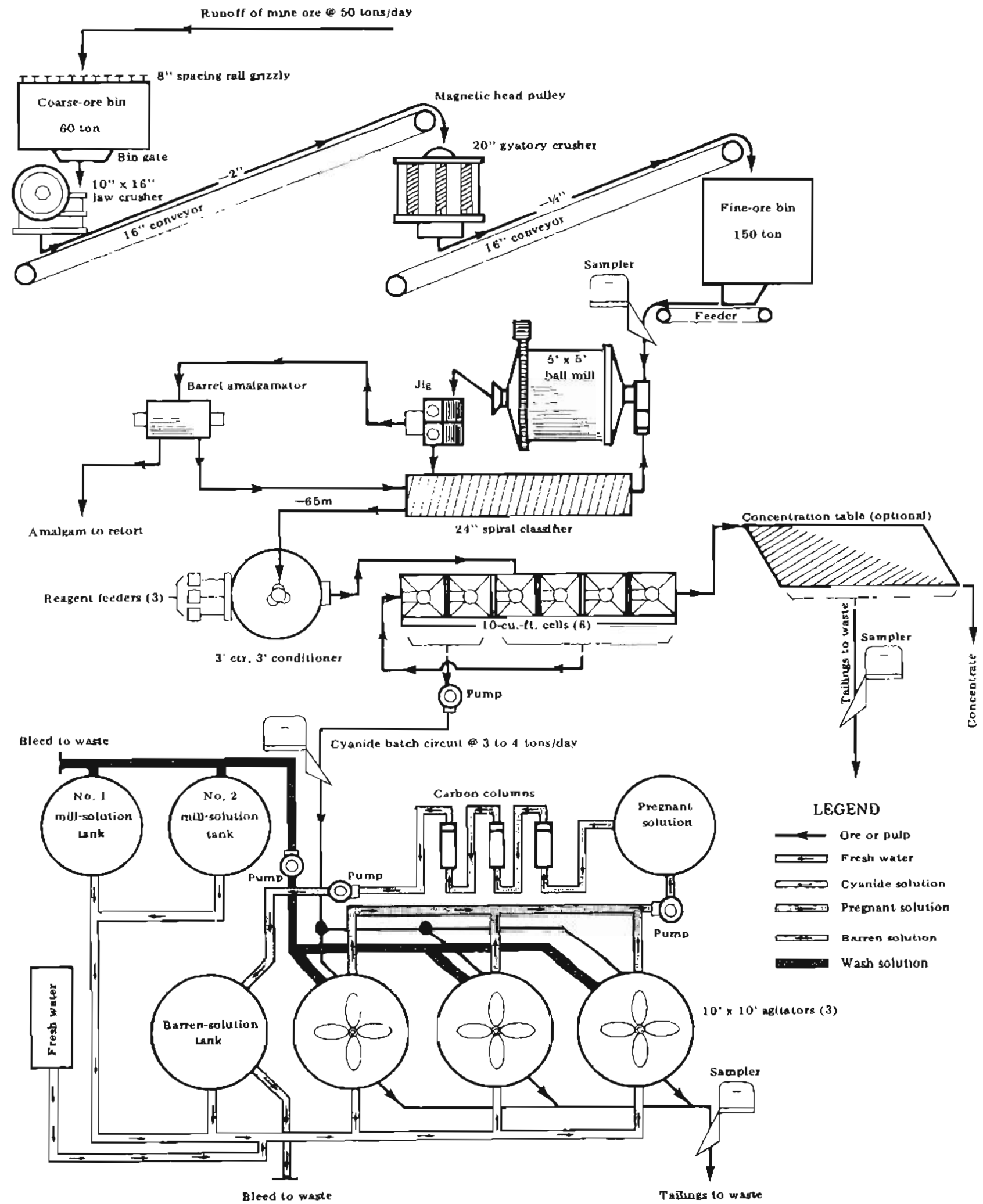

Figure 10. Flow sheel to 50-tpd gold Motation concentrator with a 4-tpd batch cyanide circuil. 
b) For classification, a 2a-in. spiral classifier was selected lo operate with the ball mill in closed circuit. (IIse of a hydrocyclone also merits investigation.)

c) for flotalion:

1) A gold particle size ol minus 65 mesh $(0.2 \mathrm{~mm})$ or less is required lor gold notalion: the tests indicate a minus 65-nesh grind is adequale for liberalion.

2) The conditioner and Dotation cells liave been sized for adequale reaction lime will the loiation reagents.

d) For the jig and amalgamacor:

1) These are considered optıonal items. but would remove coarse gold grains.

2) The now sheet shows the tajls from the amalgamator being returned to the classifier.

e) For the table:

1) The table is optional hut would provide visual control of the effirctivemess of notation.

2) The heavy nonmetallic or nonsullide minerals might be concentrated for a valuable by product.

f) For the cyanide circuit:

1) The cyanide circuil is provided as all allernative to selling the focation product to a smelter.

2) An assumption is made that at loast 48 hr of dissolution time will be required.

3) About 2.8 tpd of concentrate will be produced, bul 1 tpd was allowerl in the design.

1) The charcoal absorption columns are shown, but precipitation by inc could be considered.

The suggested now sheet should be tested by a pilot-plant test run at an established laboratory. Plant operation should determine the amount of reagents re. quired for the motation circuit, the cyanide consumplion for cyanidation, and the dissolution time.

The tests were made on samples taken on February 9. 1981. They are belicved to be representalive of the ore going to the sinall mill l'roin the o'vea villi. However. ore characteristics nua cliange as mining progresses, and pilot-plant work should be conducted before final mill design.

\section{RECOMMENDATIONS}

a) Prepare a cost analysis of the proposed litotation plant and the cyanidation batch plant.

b) Have a commercial laboratory make a continuous pilot-plant run by flotation on a representative sample of ore.

c) Evaluate these options:

Flotation with a sale of the concentrace to a smelter.

- Flotation followed by a balch cyanide process.

. Cyanidation.

\section{ACKNOWLEDGMEN'TS}

I).R. Stein assisted in collecting the samples and in the preparation, fire assaying, and sink-thoat separations. N.C. Veach completed the mincral identifications. P.D. Rao, 'T.F. Smith. [).8. Hawkins, and E.N. Wolff reviewed the manuscript and supplied helpful criticisms. Juliet Cruz of the (Iniversity of Alasta Wineral Industry' Research Laboratory completed the chemical analyses. MIRI, supplied the equipment and Dow Chemical supplicd cluc frothings agent. Silverado Mines, LLd. provided information on the operation and granted permission to publish the results of this study.

\section{REFERENCES CI'TFD}

Anselmo, (i.L., 1981, (Frant Fold Minc news release 21: Silverado Mines Lid.. 1066 West Hastings Sircet. Vancouver, B.C.. Canada, I p.

Bundtzen, 'l.K., and Kline, J.T., 1981, Geologic mine map. Grant Gold Mine, Fairbanks mining districl. N.laska: Alaska Cieological and (ienphyssical Surveys Open-file Report AOF.111. 2 p.. 1 pl. (scaled 1:120).

Glembotskii, V.A. Klassen, V.I., and Plaksin, I.N., 1963. Flotation: Primary Sources, N.Y', p. 426.

Ifeadley, N., and Tabachnick, H., 1968. Chemistry of cyanidation. Mineral dressing notes, no. 23: Amerjcan Cyananid Company. Berdan Ave., Wayne. N.J., p. 52 .

McQuisinn, F.W., and Shoemaker, R.S., 1975. Gold and silver cyanidaíion plant practice: American Instilute of Mining Engimeering Monograph, I $89 \mathrm{p}$.

Polter. C..th, 1969. Recovering gold from stripping waste and ore by percolation cyanide leaching: II.S. Bureau of Mines Technical Progress Report 20. $5 \mathrm{p}$.

Woolf, J.A., and Jackson. 'T.A., 1939, Treatment of arsenical gold ores: Canadian Mining Journal. Warch, 1939, p. $129 \cdot 130$. 


\section{STAFF}

Ross G. Schaff. State Geologist

W.W. Barnwell and W.G. Giberl. Deputy State Geologists

D.D. Adams, Geolugical assistant

M. D. Albanese, Ceological assistant

R.D. Allely, Gcological assistant

M.A. Armstrong, Puhlications specialist

M H. Ashwell, Minerals laboratory lechnician

B. (s. Baldwin, Clerk typist

E.E. Becia, Planner

T.A. Benjamin. Chemist

D.L. Berlossa, Geological ussistant

J.M. Bird, Clerk-typist

M.E. Brown, Land manageinend officer

'Г. K. Bundtzen, Geologist

C. D. Burgess, Clerk-ly'pist

L. F. Gurns, Cicological assistant

S.J. Carrick, Hydrologist

S.L. Chambers, Clerk-typist

R.A. Clay, Hydrologist

I.G. Clough, Geological assistant

E.J. Colln\%, Geological assistant

R.A. Combellick, Gcologist

P.L. Coonrod, Secrelary

C.l. Daniels, Publications specialist

N.L, Daun, Clerk-typist

J.N. Davies, Geologist

C.L. Dearhorn, Hydrologisi

J.E. Decker, Geologist

J.T. Dillon, Geolarist.

R.G. Dixon, Archaeologisi

G.R. Eakins, Geologist

S.V. Garbowski, Geolngic information technician

D.E. Gibsun, Archseolopist

J.J. Hansen, Geophysicist

S.B. Hardy, Geological assistiant

M.W. Henning, Geologisi

B.S. Hurtig, Systems analyst

C.E. Holmes, Archacologist

M.G. Inghram, Hydrologisl

R.W. Ireland, Geologist

S. A. Jacques, Cartographer

J.T. Kline, Geologist

S.L. Klingler, Archaeologist

R.W. Kornbrath, Geologist

K,J. Krause, Geologist

D.L. Krouskop, Geophysicist

G.M. Laird, Cartographer

E.M. Lamey, Administralive assistant

G.E. LaRoche, Geological assistant

F.L. Larson, Publications specia Jist

T.A. Little. Geologsist

W.E. Long, Hydrologist
W.M. Lyle, Geologist

C.L. Malhan, Accounting technician

R.A. Mann, Clerk

G.D. March, Geologist

M.A. Maurer, Hydrologist

G.A. McCoy, Hydrologisi

D.L. McGee, Geolorist

R.D. Merritt, Geologist

J.F. Meyer, Geophysicist

G.W. Mishler, ArchaeologisL

W.H. Milchell, Jr., Geological assistant

M.A. Moorman, Geologist

R.J. Motyka, Geoloyisl

C.C., Mull, Geologist

J.A. Munter, Mydrologist.

D.J. Mursch, Clerk-typist

J.N. Newgaard, Accounting teclunician

C.R. Nichols, Geologisı

K.S. Pearson, Cartographer

G.H. Pessel. Geologist

F.H. Pitts, Administrative officer

M.K. Polly, Mineral laboratory Lechuician

M.E. Pritchard, Car Lographer

S.E. Rawlinson, Geologisi

J.W. Reeder, Geologist

D.R. Reger, Archaeologist

R.D. Reger, Geologist

V.L. Reger, Clerk typist

M.S. Robinson, Geologist

L.C. Schell, Cartographer

R.D. Shaw, Archaeologisi

J.A. Sigler, Clerk

T.E. Smith, Geologist

D.J. Solie, Geologist

D.R. Slein, Chemist

R.O. Stern, Archaeologisl

C.H. Stevenson, Geologic information technician

M.J. Stroebele, Clerk-typist

K.W. Sturek, Land management techuician

B.A. Syvertson, Clerk-typist

C.A. Ulery, Geological assislant

R.G. Updike, Geologist

N.C. Veach, Chenist

R.D. Wallace, Operations reseanch analyst

J.L. Weir, Clerk-typist

S.M. Weum, Geophysicist

D.M. Wietchy, Land management of ficer

B.K. Wiison, Geological assistant

M.A. Wiltse, Chemist

G.M. Zartman, Clerk 


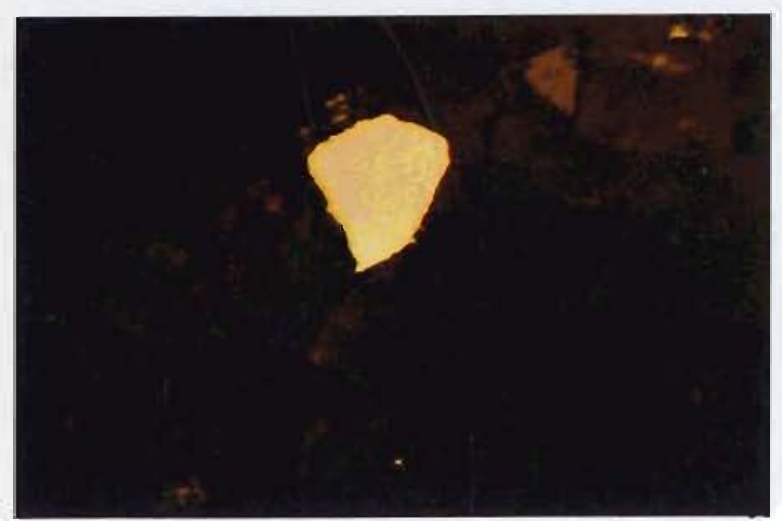

A

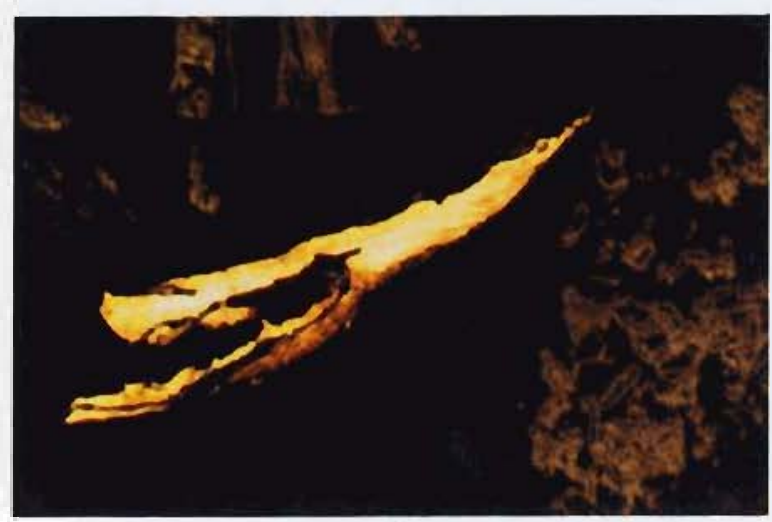

C

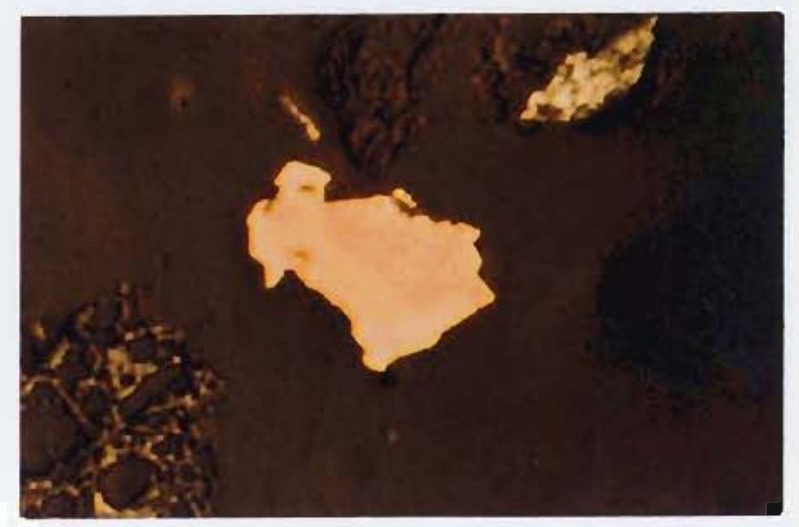

B

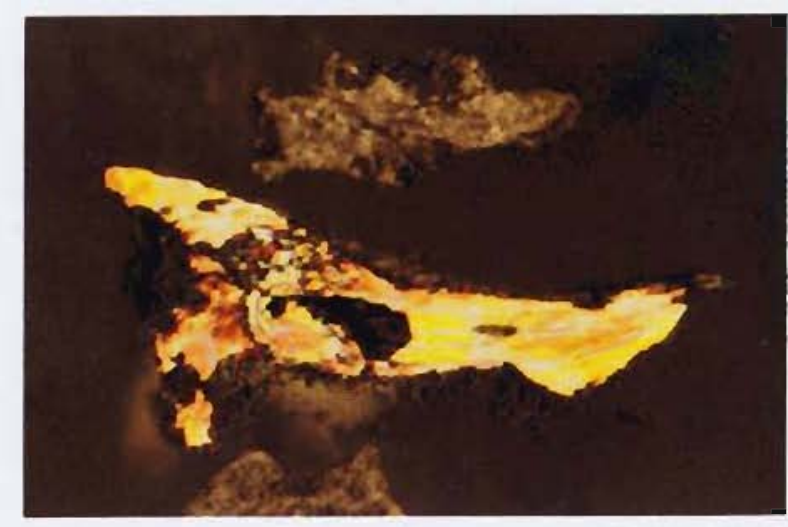

D

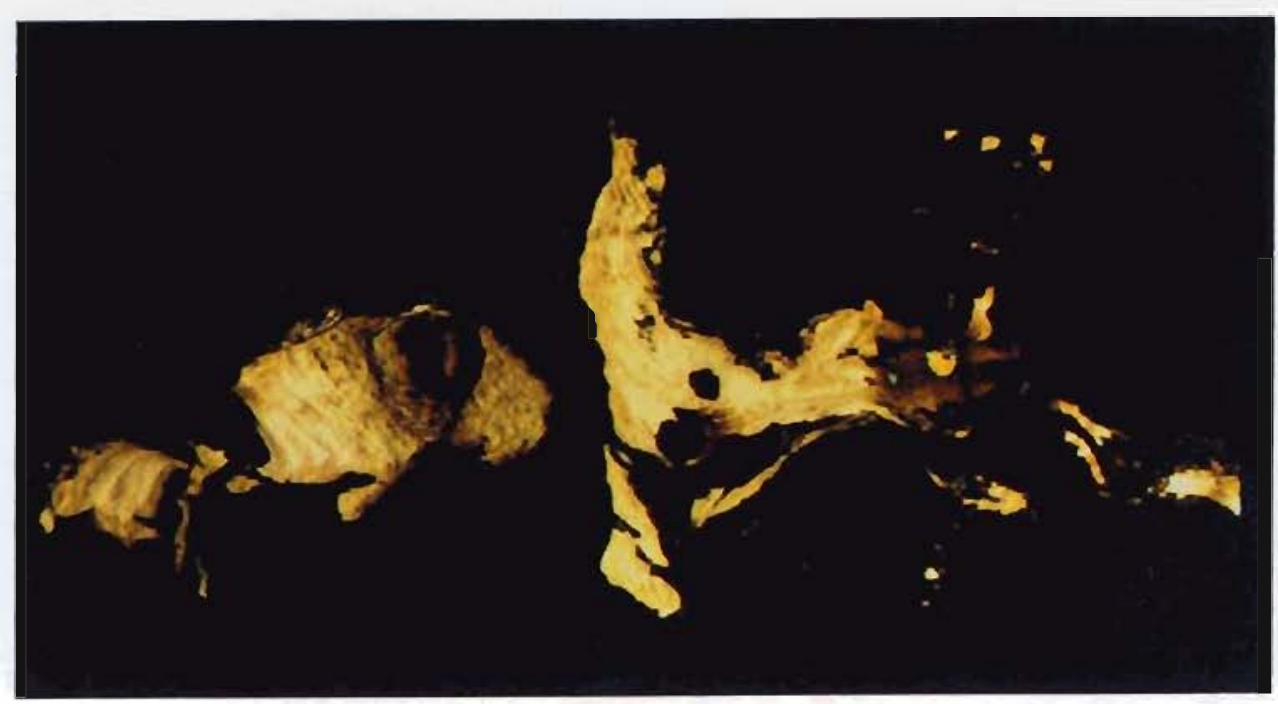

E

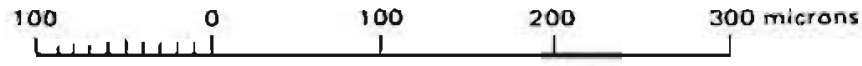

Figure 1. Photomicragraphs of gold from the Grant Gold Mine. A and B. Gold grams in a quartz matrix (polished section): C, D, and E . Cold grains from sink product in a plastic matrix. 


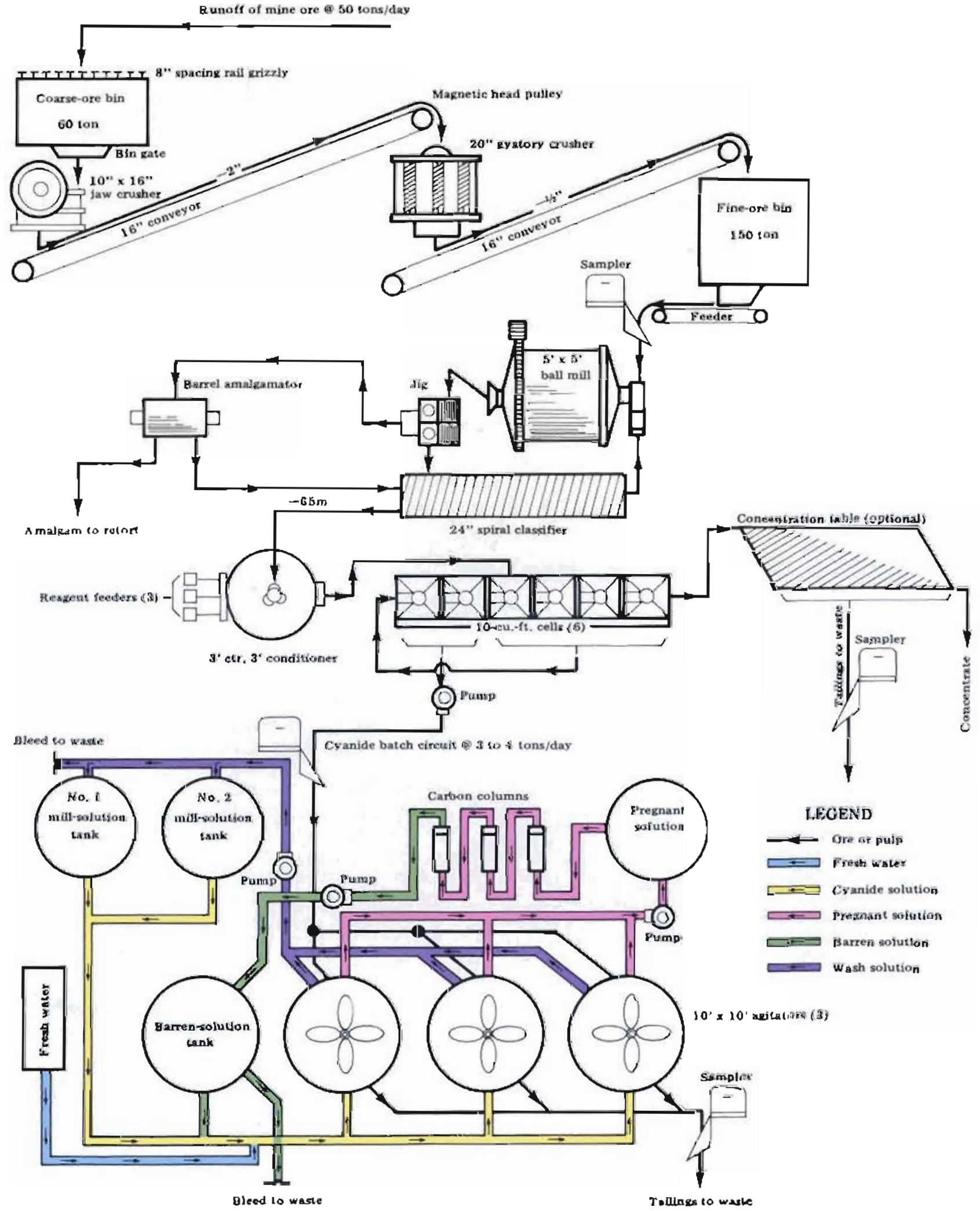

Figure 10. Flow sheet to 50-tpd gold flotation concentrator with a 4-tpd batch cyanide circuit. 